\title{
Copyright
}

by

Cafer Tayyar Ozel

2017 
The Thesis Committee for Cafer Tayyar Ozel

Certifies that this is the approved version of the following thesis:

\section{Increasing Exhaust Temperature of an Idling Light-Duty Diesel Engine through Post-Injection and Intake Throttling}

\section{APPROVED BY \\ SUPERVISING COMMITTEE:}

Supervisor:

Matthew J. Hall

Ronald D. Matthews 


\title{
Increasing Exhaust Temperature of an Idling Light-Duty Diesel Engine through Post-Injection and Intake Throttling
}

\author{
by \\ Cafer Tayyar Ozel
}

\author{
Thesis \\ Presented to the Faculty of the Graduate School of \\ The University of Texas at Austin \\ in Partial Fulfillment \\ of the Requirements \\ for the Degree of
}

Master of Science in Engineering

The University of Texas at Austin

December 2017 


\section{Acknowledgements}

Firstly, I would like to sincerely thank my advisor, Dr. Matthew Hall for the excellent guidance and invaluable support he provided during my time in graduate school. I feel very fortunate to have had the opportunity to work with him.

I am also, grateful to my family, especially my parents and my sisters, for their endless love and continuous support during this journey. I could not have come this far without them.

I would like to thank Dr. Ronald Matthews for his guidance and support.

I am thankful to Gabriela Flores, Mehmet Akif Cihan, Nazim Eryilmaz, Servet Tas and Burak Kalac for always being there for me when I needed help and support. I am so glad that our paths have crossed.

Thanks to my friends in engine research group for their support. 


\begin{abstract}
Increasing Exhaust Temperature of an Idling Light-Duty Diesel Engine through Post-Injection and Intake Throttling
\end{abstract}

\author{
Cafer Tayyar Ozel, M.S. \\ The University of Texas at Austin, 2017
}

Supervisor: Matthew J. Hall

\begin{abstract}
Modern Diesel engines rely heavily on aftertreatment systems for reducing tail pipe emissions. However, for operating conditions such as cold start, extended low load operations and idling aftertreatment systems cannot maintain a high enough temperature of approximately $200^{\circ} \mathrm{C}$ to maintain catalyst activity. In crowded urban areas actual driving conditions may significantly differ from FTP cycles due to operating under idle conditions for an extended period of time in congested traffic, long drive thru lines, traffic lights and so on. This study aimed to increase the exhaust temperature of a fully warmed-up idling light-duty Diesel engine by utilizing two methods: intake throttling and post-injection. Also, effects of these two techniques on $\mathrm{HC}$ and NOx emissions as well as IMEP and COV of IMEP were investigated. With start of injection (SOI) of post-injection being the primary variable, engine operating parameters were idle speed of 850,1100 and $1200 \mathrm{rpm}$ as well as injection pressure of 500 and 800 bar. The exhaust temperature was measured to be $105^{\circ} \mathrm{C}$ for an idle speed of $850 \mathrm{rpm}$ and WOT with no post injection. I was able to increase the exhaust temperature by nearly $65^{\circ} \mathrm{C}$ with the first method. A further increase by $25^{\circ} \mathrm{C}$
\end{abstract}


with combined use of the two methods was possible and that yielded exhaust temperatures of around $200^{\circ} \mathrm{C}$ while $\mathrm{HC}$ and $\mathrm{NO}_{\mathrm{x}}$ emissions roughly doubled. For higher engine speeds and for the heaviest throttling case exhaust temperature increased up to $240^{\circ} \mathrm{C}$ however, the engine-out $\mathrm{HC}$ emission penalty associated with this was nearly $300 \%$. For all degrees of intake throttling, maximum exhaust temperature and minimum $\mathrm{NO}_{\mathrm{x}}$ emissions were achieved for a SOI of post-injection at $25-30^{\circ} \mathrm{CA}$ aTDC and beyond this range the temperature showed a downward trend while $\mathrm{HC}$ emissions increased significantly. 


\section{Table of Contents}

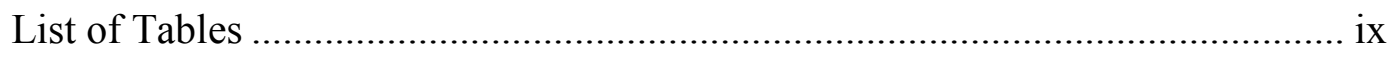

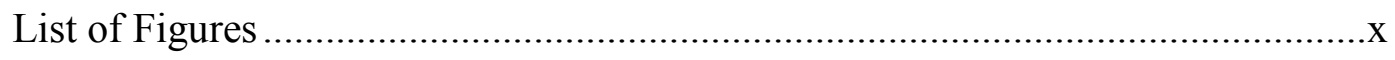

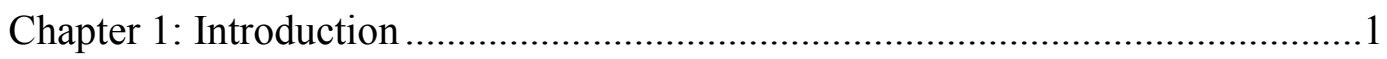

1.2 Diesel Engine Emissions and Aftertreatment Systems ...............................

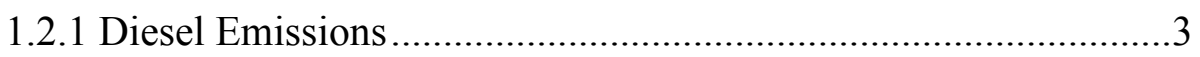

1.2.1.1 Carbon Monoxide ................................................................

1.2.1.2 Nitrogen Oxides ............................................................

1.2.1.3 Hydrocarbons .................................................................

2.2 Diesel Engine Aftertreatment Systems .............................................

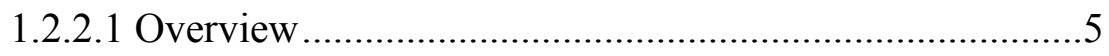

1.2.2.2 Diesel Oxidation Catalyst ..................................................

1.2.2.3 Diesel Particulate Filter.......................................................6

1.2.2.4 Selective Catalytic Reduction ............................................

Chapter 2: Experimental Setup and Methodology .................................................10

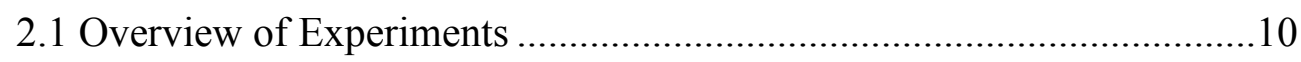

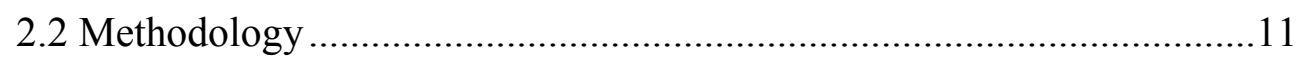

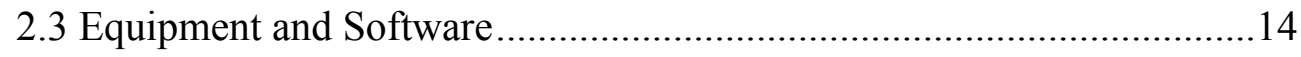

2.3.1 Non-Dispersive Infra-Red Gas Analyzer ....................................14

2.3.2 Flame Ionization Detector...........................................................14

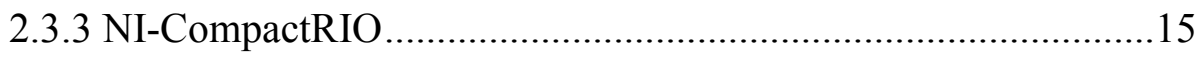

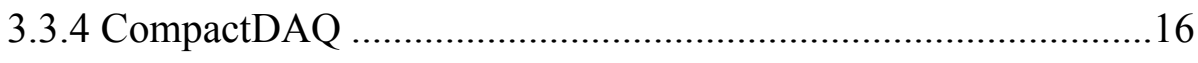

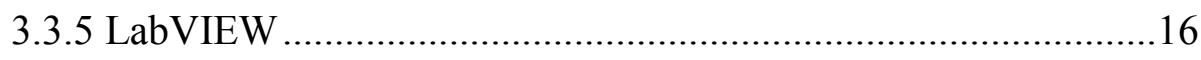

3.3.6 Combustion Analysis System ……………………………......16

Chapter 3: Engine Control Program ……………………..............................19

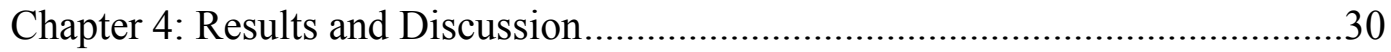

500 Bar Injection Pressure ……………………......................................

800 Bar Injection Pressure ........................................................................ 
Chapter 5: Conclusions and Future Work........................................................53

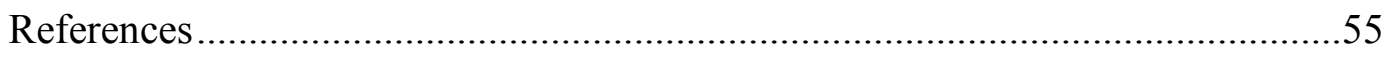




\section{List of Tables}

Table 1.1 Operating Temperature Range for Different Ammonia SCR Catalyst [23]

Table 2.1 Injection parameters of test engine and Chevrolet Cruse engine...........11

Table 2.2 GM A20DTH Engine Specifications ..............................................13 


\section{List of Figures}

Figure 1-1 HC and $\mathrm{CO}$ conversion as a factor of DOC temperature [20] .............6

Figure 1-2 Diesel particulate filter ..........................................................

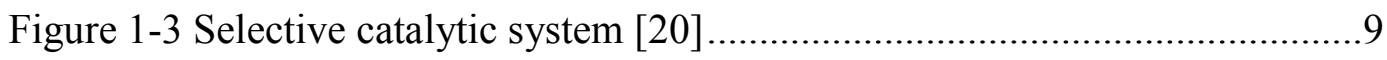

Figure 1-4 Engine, control hardware and data acquisition equipment ................13

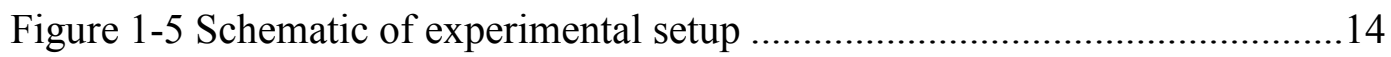

Figure 2-1 System architecture of CompactRIO [28] ..................................15

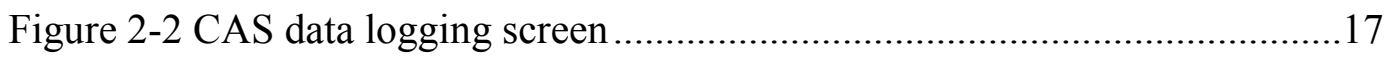

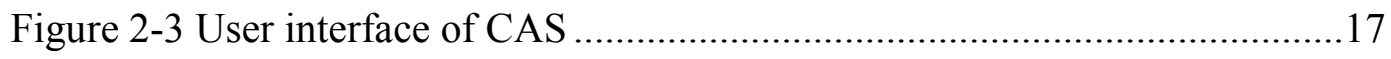

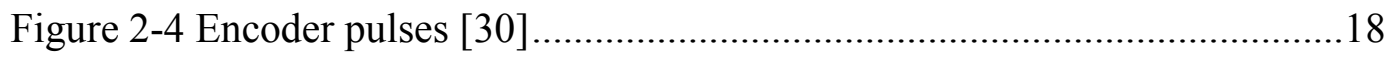

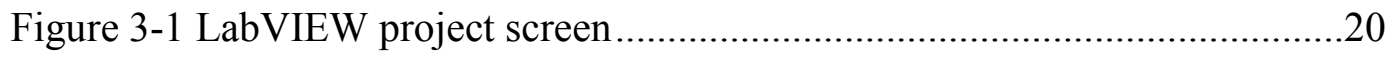

Figure 3-2 Control clusters for injection parameters. (a) Start configuration, (b) run

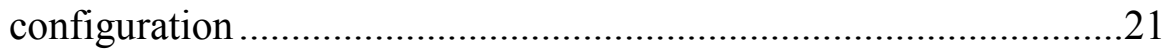

Figure 3-3 Block diagram shows modified injection cluster ............................22

Figure 3-4 Front panel of speed control program ..........................................23

Figure 3-5 Block diagrams of Speed control algorithm. (a) main algorithm, (b) sub vi for disabled configuration (c) sub vi for enabled configuration ...24

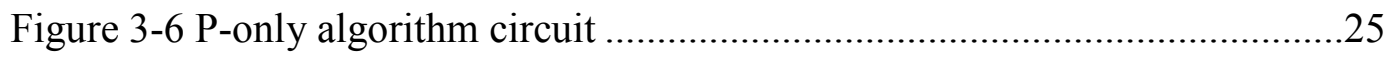

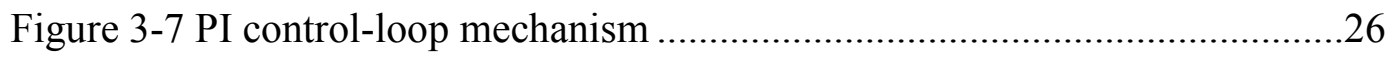

Figure 3-8 Front panel of rail pressure control program.................................27

Figure 3-9 Block diagram of rail pressure control and PWM signal generator .....27

Figure 3.10 Throttle Plate Control. (a) Block diagram, (b) front panel................29

Figure 3-11 Block diagram of data acquisition loop in LabVIEW RT................29 
Figure 4-1 Effect of SOI baseline injection strategy without post-injection on exhaust temperature, cov of IMEP and emissions (850 rpm, 500 bar

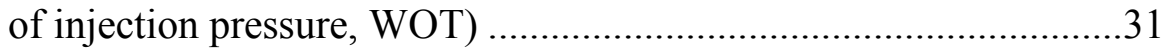

Figure 4-2 Exhaust temperature and $\mathrm{NO}_{\mathrm{x}}$ vs. injected fuel mass of $4^{\text {th }}$ injection at $25^{\circ} \mathrm{CA}$ aTDC at $850 \mathrm{rpm}, 500 \mathrm{bar}$ 32

Figure 4-3 In-cylinder pressure vs. SOI of $4^{\text {th }}$ injection at $1100 \mathrm{rpm}, 500 \mathrm{bar} . . . . .32$ Figure 4-4 . In-cylinder pressure vs. crank angle showing the effect of throttling on in-cylinder pressure $(1100 \mathrm{rpm}, 500$ bar injection pressure, post-

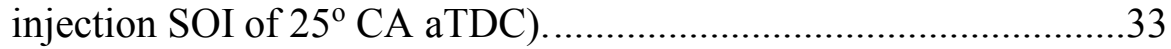

Figure 4-5 Gross and net IMEP vs. MAP (1100 rpm, 500bar injection pressure) 34

Figure 4-6 Engine-out exhaust temperature vs. SOI for the $4^{\text {th }}$ injection which is preceded by one pre-injection, a main injection and an early postinjection. The temperatures are given for various MAPs according to a degree of throttling and for an injection pressure of 500 bar, (a) 850

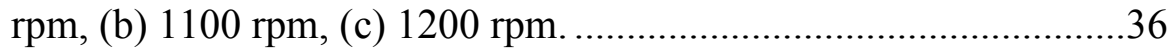

Figure 4-7 Engine out HC emissions vs. SOI of $4^{\text {th }}$ injection. The results are plotted parametrically for various MAPs (throttle position) and injection pressure of 500 bar. (a) $850 \mathrm{rpm}$, (b) $1100 \mathrm{rpm}$, (c) $1200 \mathrm{rpm}$..........38

Figure 4-8 Engine-out $\mathrm{NO}_{\mathrm{x}}$ emissions vs SOI of $4^{\text {th }}$ injection. The results are plotted parametrically for MAPs (degree of throttling) and for an injection pressure of 500 bar, (a) $850 \mathrm{rpm}$, (b) $1100 \mathrm{rpm}$, (c) $1200 \mathrm{rpm}$.........41

Figure 4-9 Duration of main injection vs. post- injection timing, $850 \mathrm{rpm}, 500$ bar of injection pressure. 41

Figure 4-10 Exhaust temperature vs. MAPs for baseline injection strategy with no post injection. $850 \mathrm{rpm}, 1100 \mathrm{rpm}, 500$ bar injection pressure. 42 
Figure 4-12 Engine-out $\mathrm{NO}_{\mathrm{x}}$ emission vs. SOI of post-injection. The results are plotted parametrically for various MAPs for an injection pressure of 800 bar, (a) $850 \mathrm{rpm}$, (b) $1100 \mathrm{rpm}$ 45

Figure 4-13 Fuel injector calibrations for 500 and 800 bar injection pressure......46

Figure 4-14 Total injection mass vs. post-injection timing for $850 \mathrm{rpm}$, relative to a baseline condition of WOT with no $4^{\text {th }}$ injection, (a) 500 bar, (b) 800 bar.

Figure 4-15 Percent increase in total injected fuel mass vs. SOI of post-injection for $850 \mathrm{rpm}, 500$ bar injection pressure 48

Figure 4-16 Percent increase in total mass vs. MAPs for Idle speed of 850 and 1100 rpm, no post-injection

Figure 4-17 COV of IMEP vs. injection timing of $4^{\text {th }}$ injection for $850 \mathrm{rpm}$, (a) 500 $\mathrm{kPa}$, (b) $800 \mathrm{kPa}$ 50

Figure 4.18 Exhaust temperature vs. MAP with 4th injection SOI of 25oCA aTDC for 500 bar injection pressure and 4th injection SOI of 30oCA aTDC for 800 bar injection pressure .51

Figure 4.19 NOx emissions vs. MAP with 4th injection SOI of 25oCA aTDC for 500 bar injection pressure and 4th injection SOI of 30oCA aTDC for 800 bar injection pressure .52 


\section{Chapter 1: Introduction}

The main goal of this study was to find methods of increasing Diesel engine exhaust temperatures under idle conditions, assisting Diesel aftertreatment systems in maintaining their light-off temperature of approximately $200^{\circ} \mathrm{C}$. This is necessary to maintain catalyst activity. The two methods used to achieve this goal were post-injection and its combined use along with intake throttling. It was thought that injecting fuel during the expansion stroke would lead to an increase in exhaust temperature due to reduced effective expansion ratio. In the second method, the air/fuel ratio was reduced by intake throttling. Also, effects of these techniques on idle stability and engine-out $\mathrm{HCs}$ as well as $\mathrm{NO}_{\mathrm{x}}$ emissions were investigated for the engine operating parameters: idle speed of 850,1100 and $1200 \mathrm{rpm}$ as well as injection pressure of 500 and 850 bar.

Manufacturers of light-duty Diesel engines are currently facing unprecedented scrutiny due to alleged emissions cheating and concerns of federal and local governments regarding the effect of Diesel emissions on urban air quality [1]. Light duty vehicles must meet emissions standards established through standardized drive cycles using chassis dynamometers, while heavy-duty Diesel engines must comply with emissions regulations established by standardized test cycles of torque and engine speed versus time on an engine dynamometer. It is recognized that these standardized tests are approximations for actual real-world driving conditions. Because actual driving practices can deviate significantly from these cycles, actual Diesel engine emissions can be significantly greater than those measured during the standard cycles, leading to prominent levels of pollutants being emitted. Modern Diesel engines rely on catalytic emissions control devices and Diesel particulate filters, some of which are catalyzed, to comply with emissions of unburned hydrocarbons, $\mathrm{CO}, \mathrm{NO}_{\mathrm{x}}$, and particulate matter. These catalytic emissions devices in the 
exhaust require heating to within a specific temperature range to be active. While there is some variability due to many factors, many of these catalytic devices must be heated to temperatures exceeding $200^{\circ} \mathrm{C}$ to function effectively [2].

There have been several previous studies of Diesel cold-idle behavior examining such issues as cycle-to cycle behavior [3] and the influence of multiple pilot injections on mixture preparation [4] [5]. Bobba et al. [6]studied the effects of post-injections on Diesel sooting tendencies.

Average emission rates of $\mathrm{HC}, \mathrm{NOx}$ and $\mathrm{CO}$ for idling light and heavy-duty vehicles was estimated by the EPA using computer models that adapted warm summer day conditions. Results were applicable to short periods of idling such as in drive-thru lines, stop lights or congested traffic. [7] In another EPA report, effects of engine speed, ambient temperature and accessory load on fuel consumption and exhaust emissions of heavy-duty trucks were experimentally investigated for warm idle condition. Various brands of truck were subjected to the test. Results showed that fuel consumption and $\mathrm{CO}_{2}$ increased in all vehicles with higher engine speed while $\mathrm{NO}_{\mathrm{x}}$ emissions behaved differently in each engine. [8]

Huang et al. [9] experimentally studied the combined effects of intake throttling and main injection retarding as well as closing the variable geometry turbine on cold-idle exhaust temperature. They varied the idle speed as a function of coolant temperature. For the coolant temperature of -30 and $10 \mathrm{C}$ idle speeds were $1100 \mathrm{rpm}$ and $850 \mathrm{rpm}$, respectively. Their results showed that it was possible to increase baseline exhaust temperature of a light duty Diesel engine idling at 850 by $131 \mathrm{C}$ by increasing idle speed to $1100 \mathrm{rpm}$ and using intake throttling along with retarded main injection. Effects of a fully closed variable geometry turbine were less than intake throttling. 
Basaran et al. [10] utilized an engine simulation model to investigate the effect of variable intake valve timing on the exhaust temperature of a low-loaded Diesel engine. The study showed that it was possible to increase exhaust temperature approximately $60{ }^{\circ} \mathrm{C}$ by either retarding or advancing intake valve closing timing. However, they found that reduced fuel consumption was achieved with early intake valve closing.

Honardar et al. [11] experimentally studied the effects of post injection, throttling, and variable valve timing on exhaust gas temperature, emissions, and fuel penalty for a light-duty Diesel engine operated at a single light load condition of 2000 rpm, 2 bar bmep and injection pressure of 600 bar with coolant temperatures of 30 and $90^{\circ} \mathrm{C}$. The 1.6 litre engine had two turbochargers configured in series. The EGR rate was varied to maintain a constant engine-out level of NOx of $60 \mathrm{ppm}$. They achieved the highest temperatures downstream of the low-pressure turbine with greater quantities of post-injection fuel, but with penalties of higher fuel consumption and emissions of $\mathrm{HCs}, \mathrm{CO}$, and $\mathrm{NO}_{\mathrm{x}}$. They were able to increase exhaust temperature by advancing exhaust valve opening which gave an earlier blow-down; the resulting expansion reduced in-cylinder $\mathrm{NO}_{\mathrm{x}}$ production allowing lower external EGR for the fixed engine-out $\mathrm{NO}_{\mathrm{x}}$ level. The lower external EGR resulted in increased internal EGR which elevated exhaust temperatures. Intake throttling increased exhaust temperature, but had "significant drawbacks regarding $\mathrm{HC}$ and $\mathrm{CO}$ emissions.

\subsection{DieSEL ENGINE EMISSIONS AND AFTERTREATMENT SYSTEMS}

\subsubsection{Diesel Emissions}

\subsubsection{Carbon Monoxide}

Carbon monoxide is colorless, odorless gas that given excessive presence in the air can cause minor or severe health problems for the human body and even may lead to death 
at higher levels. Because $\mathrm{CO}$ binds to hemoglobin 250 times stronger than does $\mathrm{O}_{2}$ it results in the formation of carboxyhemoglobin $(\mathrm{HbCO})$ hence, hemoglobin's duty of transporting oxygen is obstructed. [12] [13]

In $\mathrm{IC}$ engines $\mathrm{CO}$ is primarily the product of incomplete combustion caused generally by a rich mixture. It can be significantly problem for gasoline engines due to their occasional rich-burn operating conditions. However, despite its high air fuel ratio, Diesel engine exhaust contains $\mathrm{CO}$ as well due to large fuel droplet size and insufficient turbulence in the cylinder. [14]

\subsubsection{Nitrogen Oxides}

Nitrogen oxides is the general name for gases that contain nitrogen and oxygen. Many forms of NOx are colorless and odorless. It is one of the exhaust products regulated by the EPA because NOx emissions pose a high risk for human health by aiding the formation of ground-level ozone which cause serious respiratory problems. Motor vehicles account for $49 \%$ of all $\mathrm{NO}_{\mathrm{x}}$ emissions [15]

$\mathrm{NO}_{\mathrm{x}}$ is the product of almost all type of combustion and in internal combustion engines the main mechanism for the formation of $\mathrm{NO}_{\mathrm{x}}$ is thermal $\mathrm{NO}_{\mathrm{x}}$, also known as the Zeldovich mechanism. Thermal $\mathrm{NO}_{\mathrm{x}}$ formation occurs due to decomposition of nitrogen contained in air at high in-cylinder temperature [16]. Reaction mechanism can be expressed as:

$$
\begin{aligned}
& N_{2}+O \leftrightarrow N O+N \\
& N+O_{2} \leftrightarrow N O+O \\
& N+O H \leftrightarrow N O+H
\end{aligned}
$$




\subsubsection{Hydrocarbons}

Hydrocarbon emissions are the results of incomplete combustion, same as the CO. Poor mixing and flame quenching at early stage of combustion allow $\mathrm{HC}$ to escape destruction. [17]

\subsection{Diesel Engine Aftertreatment Systems}

\subsubsection{Overview}

In this section, details of aftertreatment systems for Diesel engines will be discussed. The primary target of this study was to examine methods to satisfy the minimum temperature requirements for aftertreatment systems to maintain catalyst activity, through increasing exhaust temperature. However, other specifications such as structural design, reduction and filtering processes, as well as reducing agents will also be briefly introduced to give an insight into commonly used reduction techniques.

\subsubsection{Diesel Oxidation Catalyst}

Diesel oxidation catalyst's (DOC) main functions can be given as conversion of $\mathrm{HC}$ and $\mathrm{CO}$ to $\mathrm{H}_{2} \mathrm{O}, \mathrm{CO}_{2}$ and $\mathrm{NO}_{2}$ through oxidization according to reactions [18]:

$$
\begin{gathered}
\mathrm{C}_{n} \mathrm{H}_{2 m}+\left(n+\frac{m}{2}\right) \mathrm{O}_{2} \rightarrow n \mathrm{CO}_{2}+\mathrm{mH}_{2} \mathrm{O} \\
\mathrm{CO}+1 / 2 \mathrm{O}_{2} \rightarrow \mathrm{CO}_{2} \\
\mathrm{NO}+1 / 2 \mathrm{O}_{2} \rightarrow \mathrm{NO}_{2}
\end{gathered}
$$

. Usually in Diesel engines NO makes up about $90 \%$ of NOx emissions and the reduction process of $\mathrm{NO}_{2}$ is faster than that of $\mathrm{NO}$ in $\mathrm{NH}_{3}-\mathrm{SCR}$. Therefore, the DOC plays a vital role in the increasing efficiency of the SCR. [19] 
The structural design of the oxidization catalyst consists of catalytic nobel metals such as platinum, palladium, rhodium on a wash coat consisting of aluminum oxide, cerium oxide and zirconium oxide.

As seen in Figure 1.1 DOC efficiency can approach over $90 \%$ for both $\mathrm{CO}$ and $\mathrm{HC}$ conversions at high operating temperature. Light-off temperature depending on the exhaust flow conditions and composition of catalyst ranges between 170 and $200{ }^{\circ} \mathrm{C}$. However, excessive temperature may lead to a sintering process that cause poor efficiency in reduction of emissions. [20] Hence, exhaust thermal management is essential for optimum DOC operations.

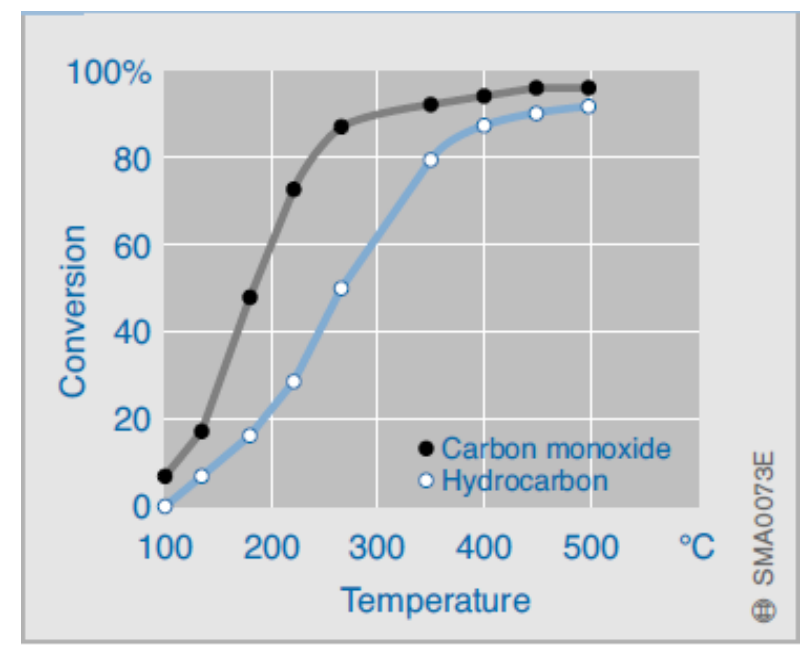

Figure 1-1 $\mathrm{HC}$ and $\mathrm{CO}$ conversion as a factor of DOC temperature [20]

\subsubsection{Diesel Particulate Filter}

The Diesel particulate filter (DPF) is used in Diesel vehicles to trap engine-out particulate matter which is suggested as one of the substantially harmful emissions produced by Diesel engines [21] . 
Among the number of different filtration media, the honeycomb ceramic monolith is the most frequently used form for DPFs. Particulate matter is captured as the exhaust stream goes through the porous wall of the ceramic monolith which is also known as 'ceramic wall flow filters'. Filtration efficiency can approach 98\%. For the filtration process shown in the Figure 1.2 exhaust gas enters the open cells from upstream and is therefore forced to flow through the porous medium to neighboring cells which allows exhaust to travel downstream, exiting the DPF. [22]

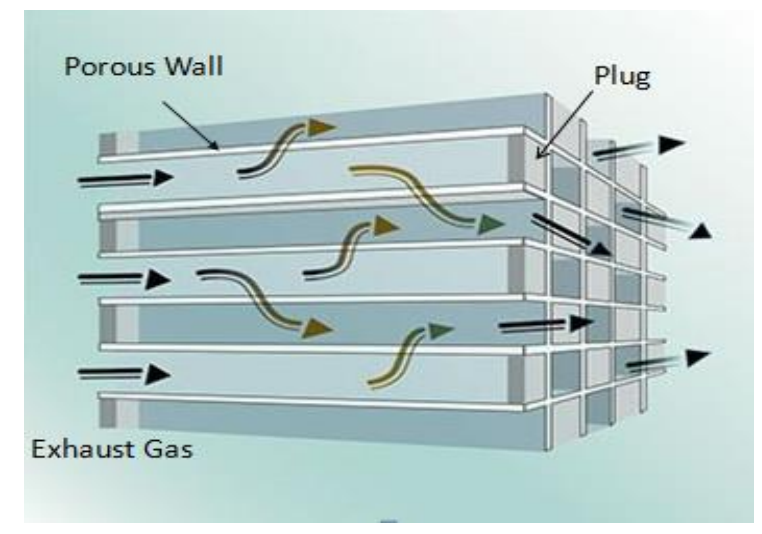

Figure 1-2 Diesel particulate filter

\subsubsection{Selective Catalytic Reduction}

Diesel engines unlike gasoline engines operates in lean-burn conditions thus, a modern three-way catalyst, that is unable to reduce $\mathrm{NO}_{\mathrm{x}}$ in the presence of excess oxygen, is not compatible with CI engines. Therefore, Selective catalytic reduction (SCR) is commonly used in light-duty and heavy-duty diesel vehicles to convert engine-out $\mathrm{NO}_{\mathrm{x}}$ to nitrogen and water. The reason it is called selective is that oxygen contained in the $\mathrm{NO}_{\mathrm{x}}$ is selectively used for oxidization rather than the molecular oxygen that exists in the exhaust gas [20] 
SCR systems use various reducing agents such as ammonia, urea and hydrocarbons, urea is the most common reductant used as an ammonia $\left(\mathrm{NH}_{3}\right)$ source in U.S., Europe and Japan. [19] The SCR process is shown in Figure1.3. Urea solution is injected into the exhaust gas which needs to be greater than $200 \mathrm{C}^{\circ}$ for evaporation and hydrolysis of urea as shown in the reaction: [23]:

$$
\mathrm{H}_{2} \mathrm{~N}-\mathrm{CO}-\mathrm{NH}_{2}+\mathrm{H}_{2} \mathrm{O} \rightarrow 2 \mathrm{NH}_{3}+\mathrm{CO}_{2}
$$

After the decomposition, urea mixture reaches the SCR unit followed by $\mathrm{NO}_{\mathrm{x}}$ conversion to nitrogen according to reaction (1) [24]:

$$
4 \mathrm{NO}+4 \mathrm{NH}_{3}+\mathrm{O}_{2} \rightarrow 4 \mathrm{~N}_{2}+6 \mathrm{H}_{2} \mathrm{O}
$$




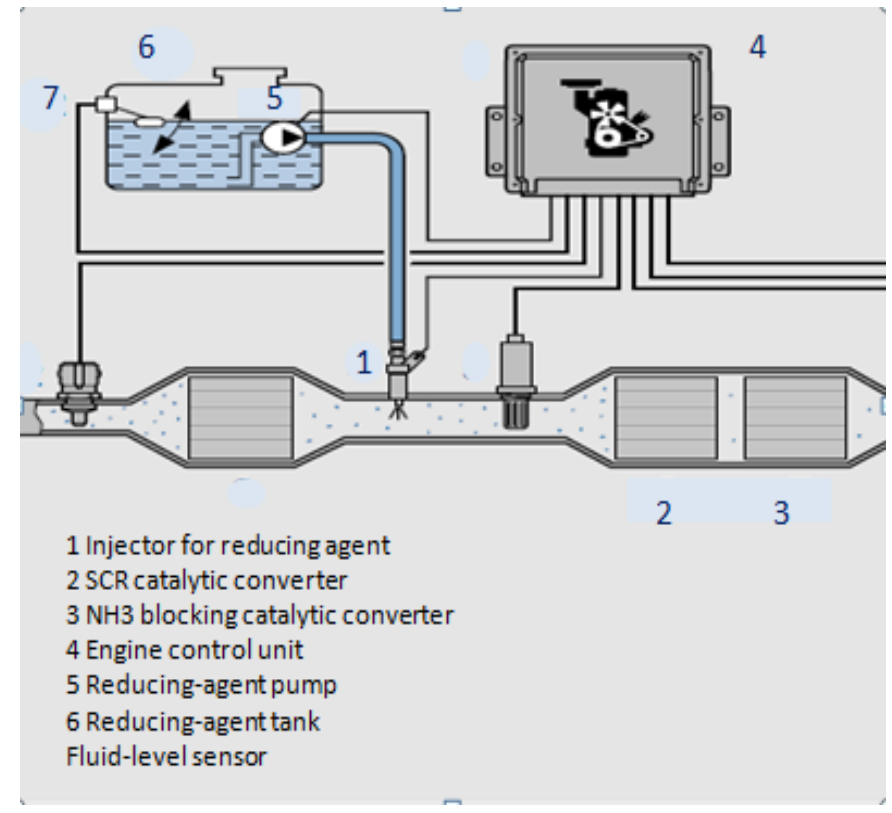

Figure 1-3 Selective catalytic system [20]

Besides urea decomposition, the nobel metal that SCR catalyst is made of determines the light off temperature as seen in the table 2.1 .

Table 1.1 Operating Temperature Range for Different Ammonia SCR Catalyst [23]

\begin{tabular}{|l|l|}
\hline SCR Catalyst Material & Operating Temperature Range $\left({ }^{\circ} \mathbf{C}\right)$ \\
\hline Platinum $(\mathrm{Pt})$ & $150-200$ \\
\hline Vanadium $\left(\mathrm{V}_{2} \mathrm{O}_{5}\right)$ & $260-450$ \\
\hline Zeolite & $300-450$ \\
\hline
\end{tabular}




\section{Chapter 2: Experimental Setup and Methodology}

\subsection{OVERVIEW OF EXPERIMENTS}

This study investigated two methods to increase the exhaust temperature of a Diesel engine under idle conditions: post injection of fuel after TDC and intake throttling. A postinjection of fuel after TDC during the expansion stroke was added to the baseline idle injection strategy for the first method. The idea behind the first method was that with additional fuel combined with a reduced effective expansion ratio, post-combustion would lead to higher exhaust temperature. In other words, reducing the thermal efficiency in favor of higher exhaust temperature. In the second method, throttling of the intake air to reduce the air/fuel ratio was used conjointly with the first technique.

The baseline injection strategy was adapted from a 2014 Chevrolet Cruze that has an engine almost identical to the GM engine used for this study. Injection parameters of the test engine such as the number of injections, the time between injections and injection durations were measured using an oscilloscope while the engine was fully warmed-up and idling at $850 \mathrm{rpm}$. However, it was not possible to measure injection pressure because of not having the rail pressure sensor calibration for the Cruze engine. It was found that the production engine uses four injections per cycle at idle condition: two pilot injections, a main injection and a post-injection. Applying this injection strategy to the test engine resulted in nearly the same idle speed. To investigate the effect of the above-mentioned methods a second post injection was added after the $4^{\text {th }}$ injection however because of the additional fuel's contribution to the IMEP, the engine was not able to maintain the necessary low idle speed thus the baseline injection strategy was modified by dropping the

$2^{\text {nd }}$ injection in favor of a second post-injection. Injection specifications of Chevrolet Cruze engine and the test engine are given in Table 2.1 
Table 2.1 Injection parameters of test engine and Chevrolet Cruse engine

\begin{tabular}{|c|c|c|c|}
\hline Injection parameter & $\begin{array}{l}\text { Cruze } \\
\text { engine }\end{array}$ & $\begin{array}{l}\text { Test engine } \\
\text { (average } \\
\text { case) }\end{array}$ & $\begin{array}{l}\text { Injected fuel } \\
\text { mass for } \\
\text { Test engine } \\
\text { (average }\end{array}$ \\
\hline Duration or mass of $1^{\text {st }}$ pilot & $0.23 \mathrm{~ms}$ & $0.3 \mathrm{~ms}$ & $0.52 \mathrm{mg}$ \\
\hline $\begin{array}{l}\text { Time between SOI of } 1^{\text {st }} \text { pilot } \\
\text { and SOI of } 2^{\text {nd }} \text { pilot } \\
\text { for Cruze engine }\end{array}$ & $1.4 \mathrm{~ms}$ & N/A & N/A \\
\hline Duration of $2^{\text {nd }}$ pilot & $0.22 \mathrm{~ms}$ & $\mathrm{~N} / \mathrm{A}$ & $\mathrm{N} / \mathrm{A}$ \\
\hline $\begin{array}{l}\text { Time between SOI of } 2^{\text {nd }} \text { pilot } \\
\text { and SOI of main inj. } \\
\text { for Cruze or } 1^{\text {st }} \text { inj. and main } \\
\text { inj. of test engine }\end{array}$ & $1 \mathrm{~ms}$ & $2.33 \mathrm{~ms}$ & \\
\hline $\begin{array}{l}\text { Duration or mass of main } \\
\text { injection }\end{array}$ & $0.45 \mathrm{~ms}$ & $0.31 \mathrm{~ms}$ & $0.38 \mathrm{mg}$ \\
\hline $\begin{array}{l}\text { Time between SOI of main } \\
\text { injection and SOI of } 4^{\text {th }} \text { inj. for } \\
\text { Cruze or } 3^{\text {rd }} \text { injection for Test }\end{array}$ & $2.08 \mathrm{~ms}$ & $2.04 \mathrm{~ms}$ & \\
\hline $\begin{array}{l}\text { Duration or mass of } 4^{\text {th }} \text { injection } \\
\text { Cruze or } 3^{\text {rd }} \text { injection of Test } \\
\text { engine }\end{array}$ & $0.36 \mathrm{~ms}$ & $0.3 \mathrm{~ms}$ & $0.52 \mathrm{mg}$ \\
\hline $\begin{array}{l}\text { Time between SOI of } 4^{\text {th }} \text { inj. } \\
\text { and SOI of } 5^{\text {th }} \text { inj. for Cruze or } \\
3^{\text {rd }} \text { injection and } 4^{\text {th }} \text { inj. for Test } \\
\text { engine }\end{array}$ & N/A & $4.11 \mathrm{~ms}$ & \\
\hline $\begin{array}{l}\text { Duration or mass of } 5^{\text {th }} \text { injection } \\
\text { Cruze or } 4^{\text {rd }} \text { injection of Test } \\
\text { engine }\end{array}$ & NA & $0.3 \mathrm{~ms}$ & $0.52 \mathrm{mg}$ \\
\hline \multicolumn{3}{|l|}{ Total Injected fuel mass } & $1.94 \mathrm{mg}$ \\
\hline
\end{tabular}

\subsection{Methodology}

The engine used for the study was a GM A20DTH light duty Diesel engine. Specifications for the engine are given in Table 2.2. For operational simplicity the turbocharger was removed because the focus of this study was idle conditions under which manifold air pressure (MAP) is approximately atmospheric 
The engine as shown in Fig 2.1 was connected to an electric dynamometer however the dynamometer was not active for this study. A LabVIEW based engine control program was developed and modified by adding parallel proportional-integral control algorithms to maintain the desired idle speed, rail pressure and throttle position. The duration of the $2^{\text {nd }}$ injection that was also the main injection was used as the control variable in the idle speed control loop. The 8-slot reconfigurable C-RIO system and control modules were used for implementing the control software and logging some engine parameters including $\mathrm{NO}_{\mathrm{x}}$ and $\mathrm{CO}_{2}$ emissions. NI Combustion analysis system software was used along with a NI-cDAQ system for engine data acquisition. A Continental Model NB1500 $\mathrm{NO}_{\mathrm{x}}$ sensor was located in the exhaust just downstream of the exhaust manifold; this was also the location of exhaust gas extraction for measurements of HCs which were measured using a Rosemount Analytical Model 400A FID. The estimated uncertainties in the measurements were based upon instrument accuracy as given by the manufacturers, calibration reproducibility, and day-to-day reproducibility of replicate data from engine operation. The precision of the temperature measurements was estimated to be within $+/-2^{\circ} \mathrm{C}$, and data were replicated within $+/-5^{\circ} \mathrm{C}$. The $\mathrm{NO}_{\mathrm{x}}$ emissions were reproducible within $+/-3 \%$, with the precision being higher for measurements made during a given data run. The FID based HC measurements are presented on $\mathrm{a}_{3}$ (propane) basis. They were more variable from dayto-day, the precision of the measurements was within $+/-2 \%$, but with day-to-day variation, accuracy was estimated at approximately $+/-4 \%$.

Engine operating conditions to be studied were chosen as idle speed of 850,1100 and $1200 \mathrm{rpm}$ and two rail pressures of 500 and 800 bar with the engine fully warmed-up with coolant temperature at $86{ }^{\circ} \mathrm{C}$. Under these conditions the two primary variables were injection timing of the $4^{\text {th }}$ injection (post-injection) and MAP. 
Table 2.2 GM A20DTH Engine Specifications

\begin{tabular}{|l|l|}
\hline Displaced volume & $1956 \mathrm{cc}$ \\
\hline Stroke & $90.4 \mathrm{~mm}$ \\
\hline Bore & $83.0 \mathrm{~mm}$ \\
\hline Connecting rod length & $145 \mathrm{~mm}$ \\
\hline Compression ratio & $16.5: 1$ \\
\hline Valve diameter I/E & $28.5 / 25.5 \mathrm{~mm}$ \\
\hline Number of valves/cylinder & 4 \\
\hline Exhaust Valve Open & $52^{\circ} \mathrm{bBDC} @ 0.1 \mathrm{~mm}$ lift $[10]$ \\
\hline Exhaust Valve Close & $10^{\circ} \mathrm{bTDC} @ 0.1 \mathrm{~mm}$ lift \\
\hline Inlet Valve Open & $8^{\circ} \mathrm{bTDC} @ 0.1 \mathrm{~mm}$ lift \\
\hline Inlet Valve Close & $40^{\circ} \mathrm{aBDC} @ 0.1 \mathrm{~mm}$ lift \\
\hline Manufacturer's specified idle speed & $850 \mathrm{rpm}$ \\
\hline
\end{tabular}

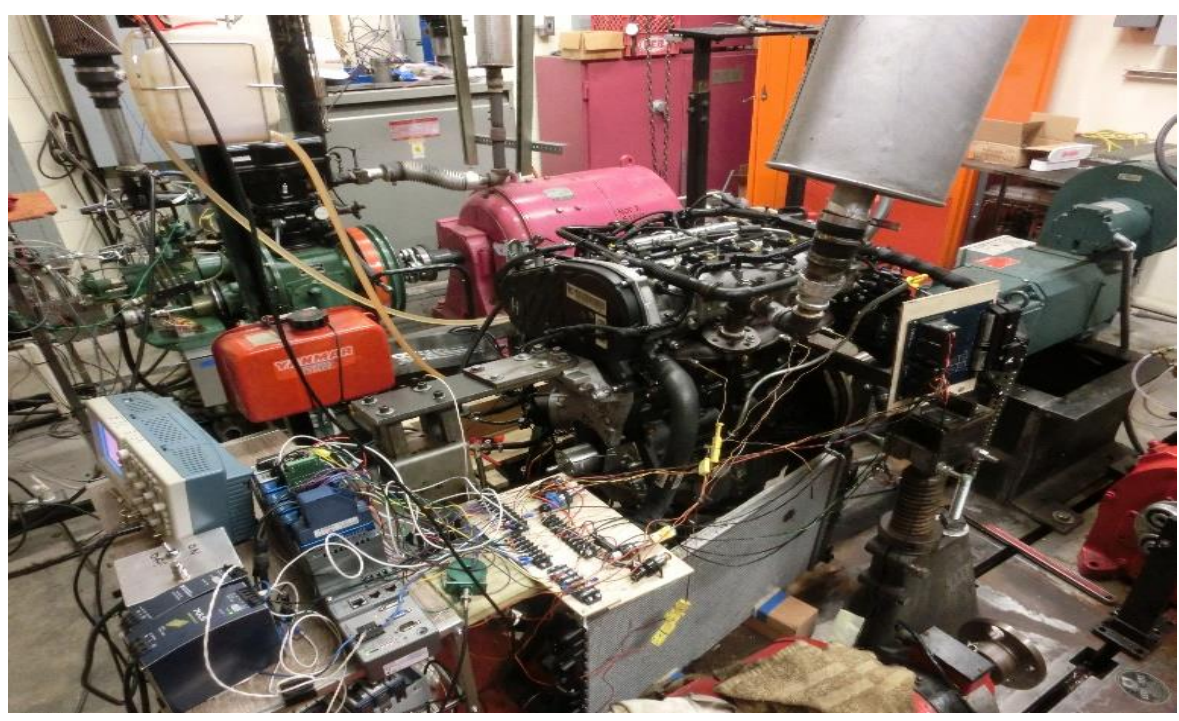

Figure 1-4 Engine, control hardware and data acquisition equipment 


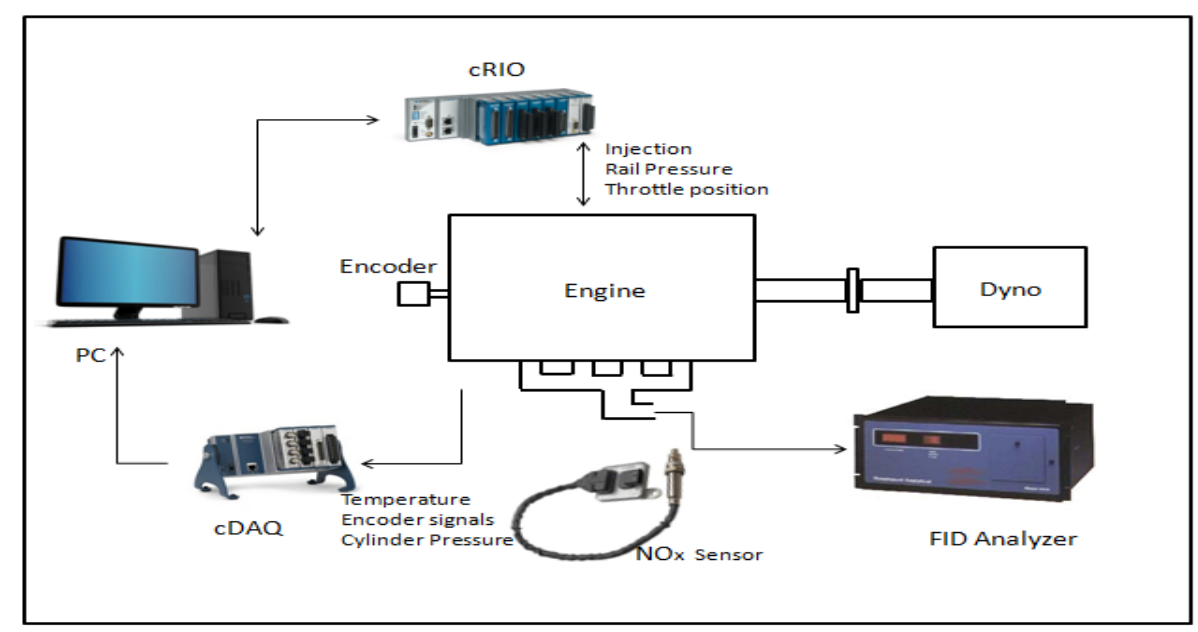

Figure 1-5 Schematic of experimental setup

\subsection{EQUIPMENT AND SOFTWARE}

\subsubsection{Non-Dispersive Infra-Red Gas Analyzer}

Non-Dispersive Infra-Red (NDIR) gas analyzers can be used for measuring exhaust gas components including $\mathrm{CO}_{2}, \mathrm{CO}, \mathrm{HC}, \mathrm{NO}, \mathrm{O}_{2}$ and $\mathrm{SO}_{2}$ [25]. In this study, only the concentration of $\mathrm{CO}_{2}$ was measured using an NDIR analyzer.

In an NDIR analyzer an infra-red beam discharged by an IR emitter goes through the gas sample and the amount of infrared radiation absorbed by the sample is measured at the necessary wavelength to find the molar concentration of $\mathrm{CO}_{2}$. [26]

\subsubsection{Flame Ionization Detector}

The flame ionization detector (FID) is a method of measuring HC concentration. In the flame chamber sample gas is introduced to the flame of the FID which is fueled, with $60 \%$ nitrogen and $40 \%$ hydrogen. HC's in the sample gas create ions when they are burnt. Ions are detected by the metal collector and the current across these metals which is proportional to the rate of ionization gives the $\mathrm{HC}$ concentration in the sample gas. [27] 


\subsubsection{NI-CompactRIO}

A NI compact-RIO (c-RIO) is an embedded system that consists of a real-time processor, a reconfigurable FPGA and I/O modules. In Figure 2.1 the system architecture of the c-RIO is shown. Users can build control and monitoring applications for the c-RIO using NI LabVIEW as well as Real-time and FPGA modules. The c-RIO can be connected to almost any sensor and actuator with more than 50 compatible NI C series I/O modules. Control applications for the c-RIO are used in wide variety of testing and experimental studies including the particle accelerators controls at CERN and hardware-in-the-loop testing for engine control units as examples.[28]

An FPGA is a programmable chip that consists of three main components these are logic block, programmable interconnects and I/O blocks. Its direct access to I/O modules makes FPGA crucial for controller systems that requires fast control loops and high speed I/O buffering from the devices such as the encoder, cam and crank sensors. Therefore, it allowed us to control the engine smoothly. A Single c-RIO chassis can execute more than 20 PID control loops conjointly through FPGA at a rate of $100 \mathrm{kHz}$. Additionally, real time controller programs can access I/O with less than $500 \mathrm{~ns}$ of delay between loops with the help of FPGA [28]

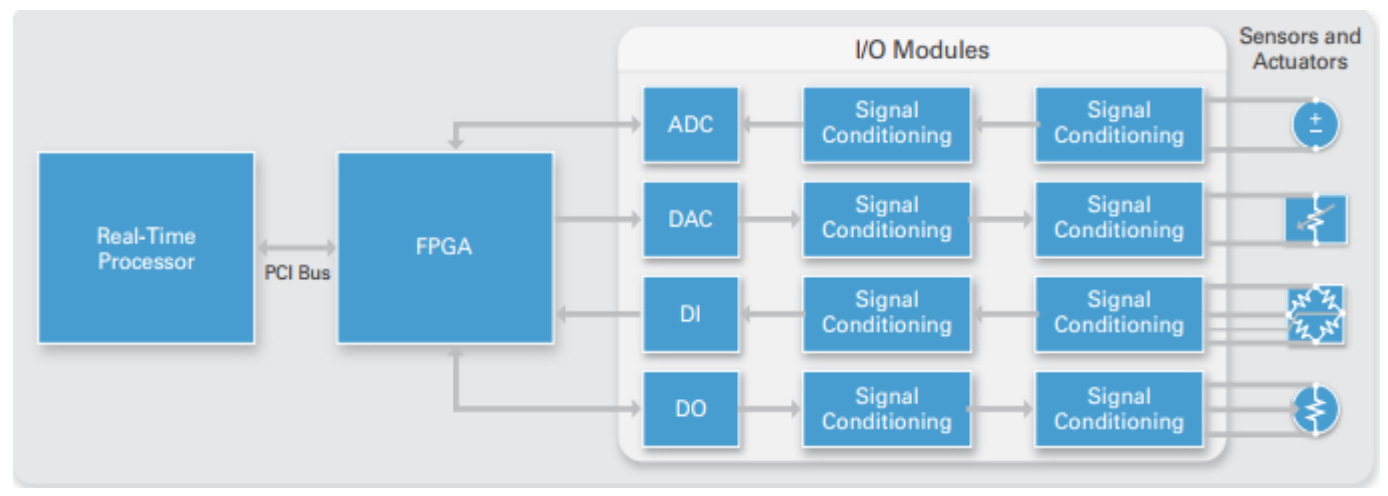

Figure 2-1 System architecture of CompactRIO [28] 


\subsubsection{CompactDAQ}

CompactDAQ (cDAQ) systems are used mainly for data acquisition purposes, and are composed of a chassis and C-series modules. Signal conditioning, digital/analog conversions to generate analog output signals, measuring and controlling digital I/O as well as providing signal conditioning are the tasks performed by cDAQ systems. [29]

In the experiments conducted in our lab, a thermocouple module, analog module and digital module were placed in slots of cDAQ chassis to measure exhaust temperatures, cylinder pressure, manifold air pressure and the encoder signals.

\subsubsection{LabVIEW}

LabVIEW is graphical programming software created by National Instrument used for process monitoring, test, measurement and control applications.

\subsubsection{Combustion Analysis System}

Combustion analysis system (CAS) software created by National Instruments was used in this experimental study for data acquisition such as exhaust temperature, cylinder pressure vs. CA as well as calculating results, for IMEP, COV IMEP and mass fraction burned being an example. As seen in Figure 2.2 logging data to file continuously, by cycle

count, time or file size was available. For this study, data acquisition by cycle count option was used. 


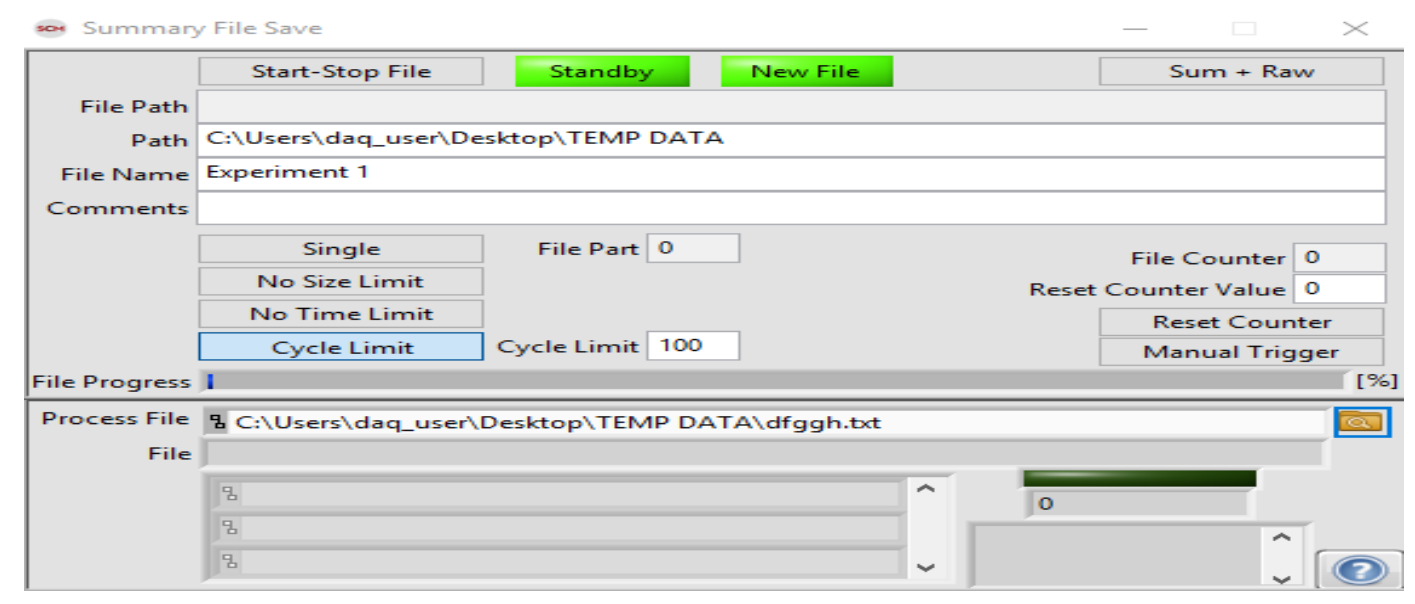

Figure 2-2 CAS data logging screen

As shown in Figure 2.3 the user interface of the CAS software consists of two sections: configuration and results. Configuration of general setup such as engine geometry, encoder and I/O hardware setup for instance assigning sync analog channels can be changed solely in the offline mode.

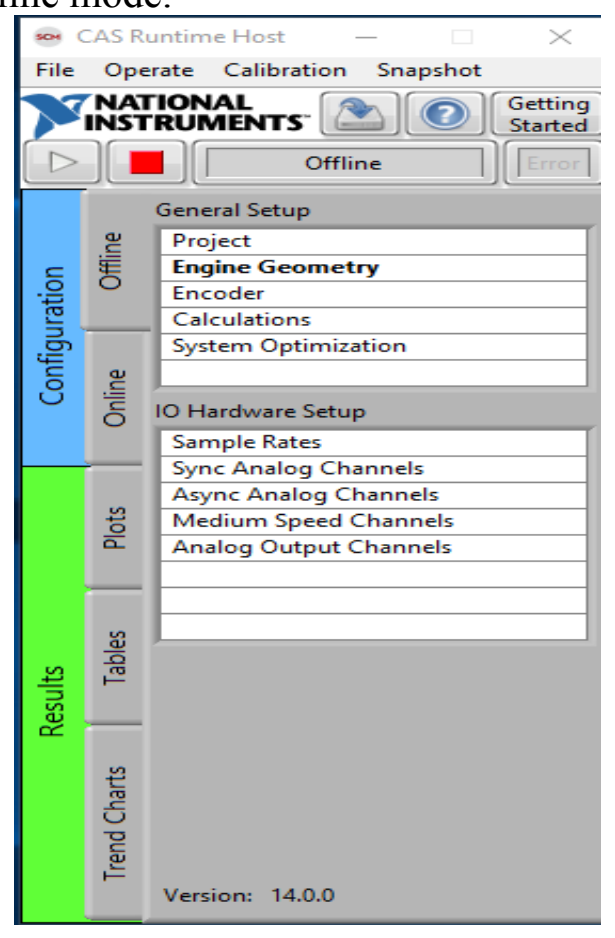

Figure 2-3 User interface of CAS 
Two primary pieces of equipment required in order for the CAS software to function are an encoder and a data acquisition device. Encoder signals as shown in Figure 2.4 include patterns of $\mathrm{A}, \mathrm{B}$ and $\mathrm{Z}$ pulses and are used for engine positions tracking to synchronize the DAQ sampling. Number of A pulses per revolution determines the resolution of the encoder. [30] The $\mathrm{Z}$ pulse occurs once per revolution and it needs to be synchronized with the piston at TDC. A model XH25 BEI industrial encoder which has a resolution of 720 pulses per revolution was used in this study

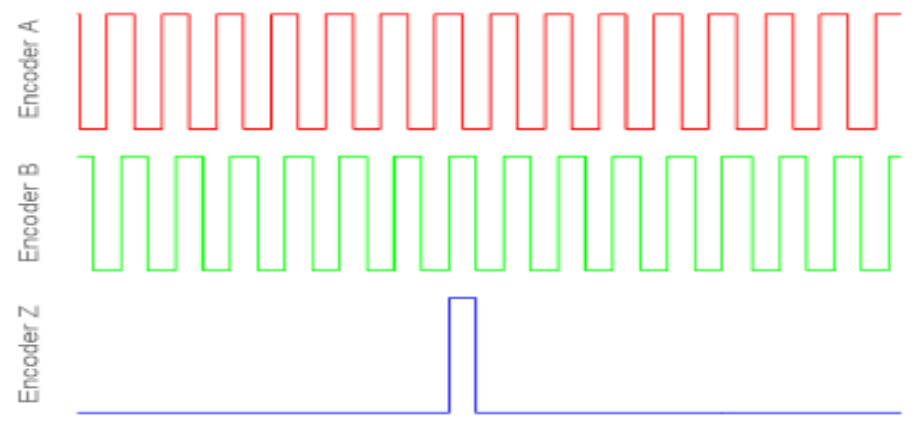

Figure 2-4 Encoder pulses [30]

Even though the cylinder pressure sensor is not required by CAS to run, most of the calculations and analysis results will not be available unless the software gets a proper pressure signal.

Besides data logging, advantages of real-time monitoring of the raw data and calculated results allows the user to adjust parameters correctly and identify and solve problems such as encoder misalignment. 


\section{Chapter 3: Engine Control Program}

A LabVIEW based program was developed to control the engine through the c-RIO chassis. The program consisted of Real-Time and FPGA VIs. In addition to engine control data logging of engine parameters was done, such as engine speed, rail pressure, injection timing as well as throttle position and injection duration. Additionally, monitoring and sampling of $\mathrm{HC}, \mathrm{NO}_{\mathrm{x}}$ and $\mathrm{CO}_{2}$ emissions was possible by adding analog and $\mathrm{CAN}$ modules to the c-RIO systems. All engine position tracking and PWM signal generation tasks were performed by FPGA and Real-time VI modified accordingly so that all the parameters could be monitored and changed using RT VI.

To run the engine, the LabVIEW user interface project named DI3 is opened. The project screen as shown in Figure 3.1 includes an RT VI, FPGA VI, I/O modules as well as sub-VI and target device which was the c-RIO in our case. Then, the RT and FPGA VI is opened and run after all necessary engine parameters are entered correctly. 


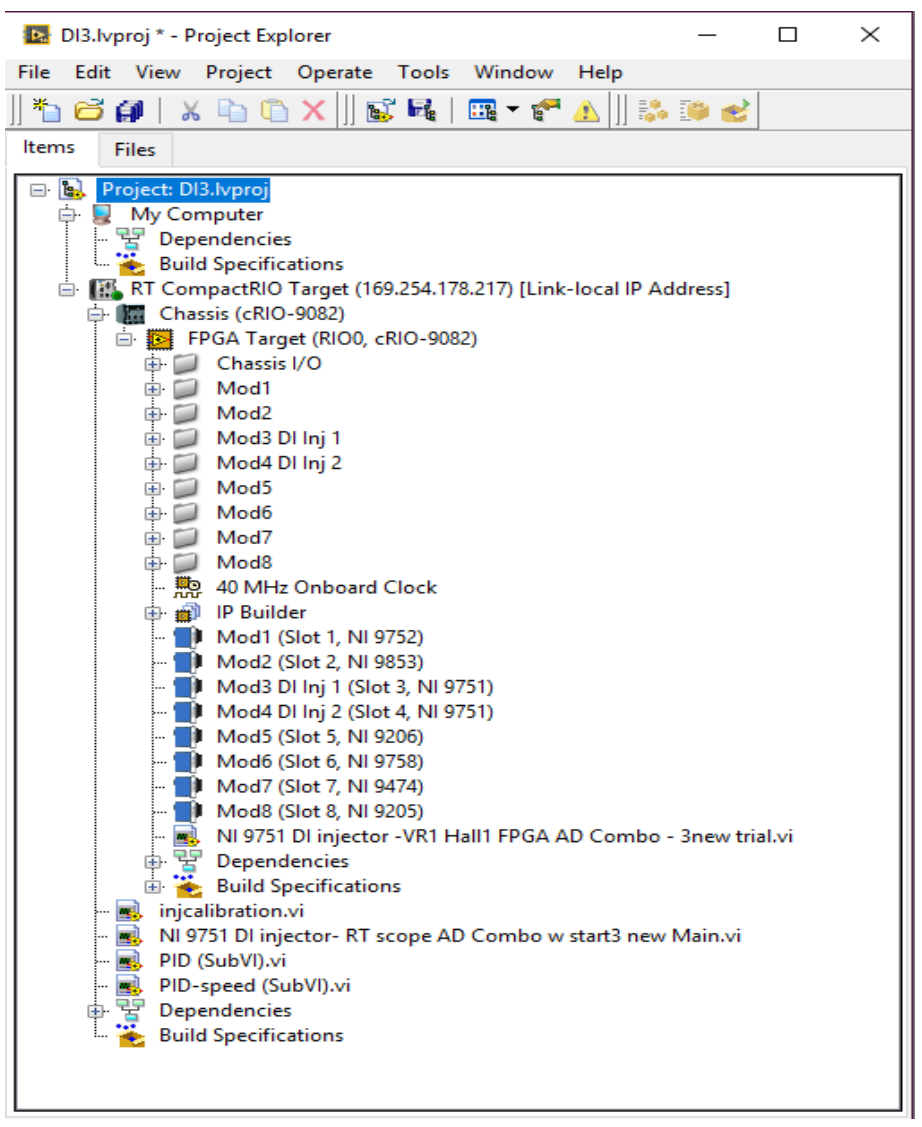

Figure 3-1 LabVIEW project screen

The FPGA and RT VI must be running simultaneously for the engine to maintain its operation. Because the FPGA is the main VI compiled in the chip that is placed in the cRIO chassis and directly communicates with I/O modules. Any changes made in the parameters in the RT either manually or automatically are applied to control hardware through the FPGA.

In the Real Time front panel, the first thing to do is enabling injectors for each cylinder if all cylinders are needed to be fired in the experiment. Later, injection strategy is implemented using two injection configuration clusters as shown in Figure 3.2. Both clusters include control and boolean terminals for injection parameters such as injection duration and injection timing for 5 injections for a single cycle. The Number of injections 
used per cycle is also controlled by an enable/disable button. Parameters entered in the cluster named PlsGen_config_start are used only for starting the engine and applied over the engine speed ranging from 0 to $700 \mathrm{rpm}$ due to high amount of fuel required to start the engine. Beyond $700 \mathrm{rpm}$, injection parameters transition from start configuration to run configuration and injection parameters entered in the run configuration cluster are used as long as engine maintains the speed above the transitioning speed. Injection timing of 0 did not correspond to TDC for some reason, and the crank angle timing offset function that is part of the Drivven engine control VI in the FPGA program did not work for some reason, thus, using an oscilloscope it was found that injection timing of -110 in the software actually represents 0 degree aTDC. As an example, -120 corresponded to $10^{\circ} \mathrm{CA}$ aTDC.

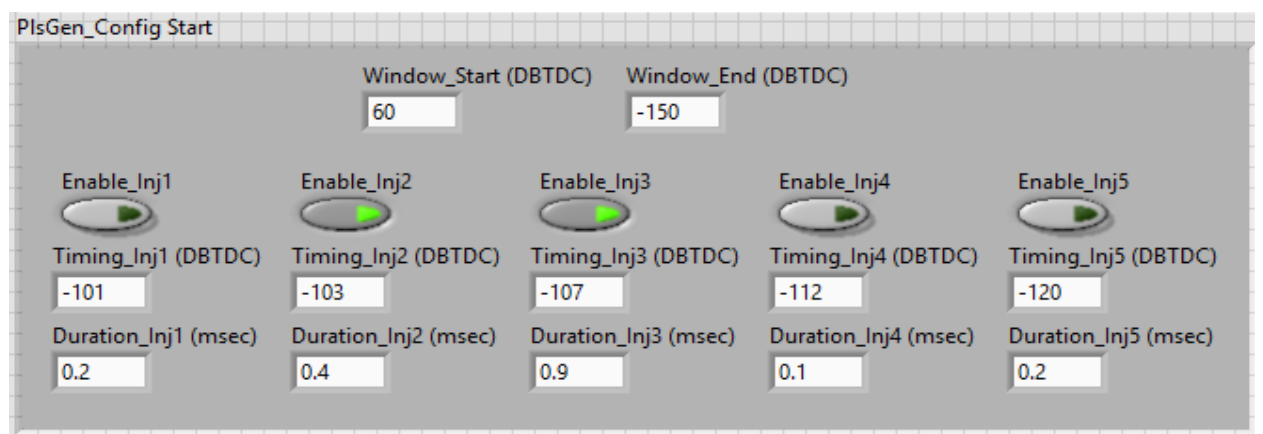

(a)

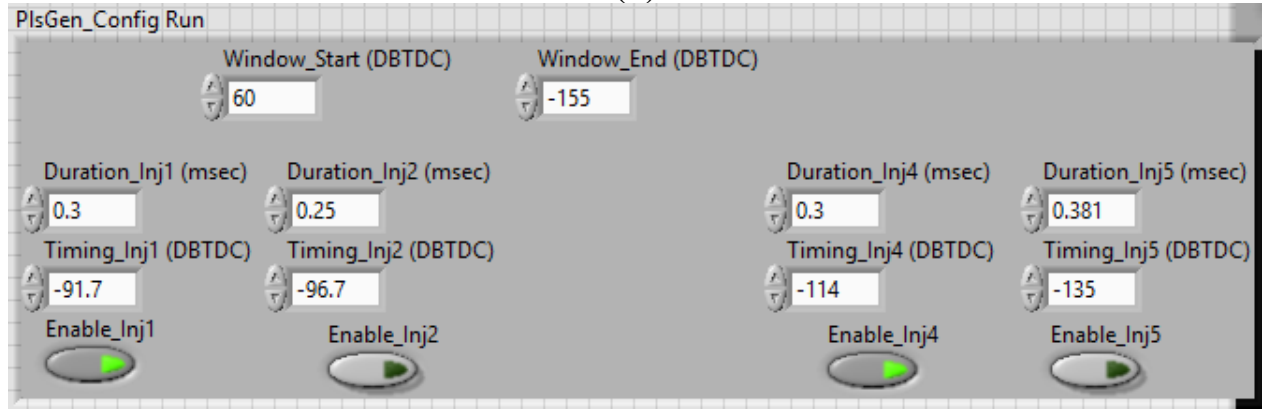

(b)

Figure 3-2 Control clusters for injection parameters. (a) Start configuration, (b) run configuration 
Normally injection clusters allow only manual change of parameters. However, the run configuration was modified to the remove $3^{\text {rd }}$ injection out of the cluster an a Proportional-Integral (PI) based speed control loop was developed to automatically vary the injection duration of $3^{\text {rd }}$ injection to maintain idle speed. As seen in the Figure 3.3 the $3^{\text {rd }}$ injection was removed from the cluster by utilizing unbundling and bundling functions.

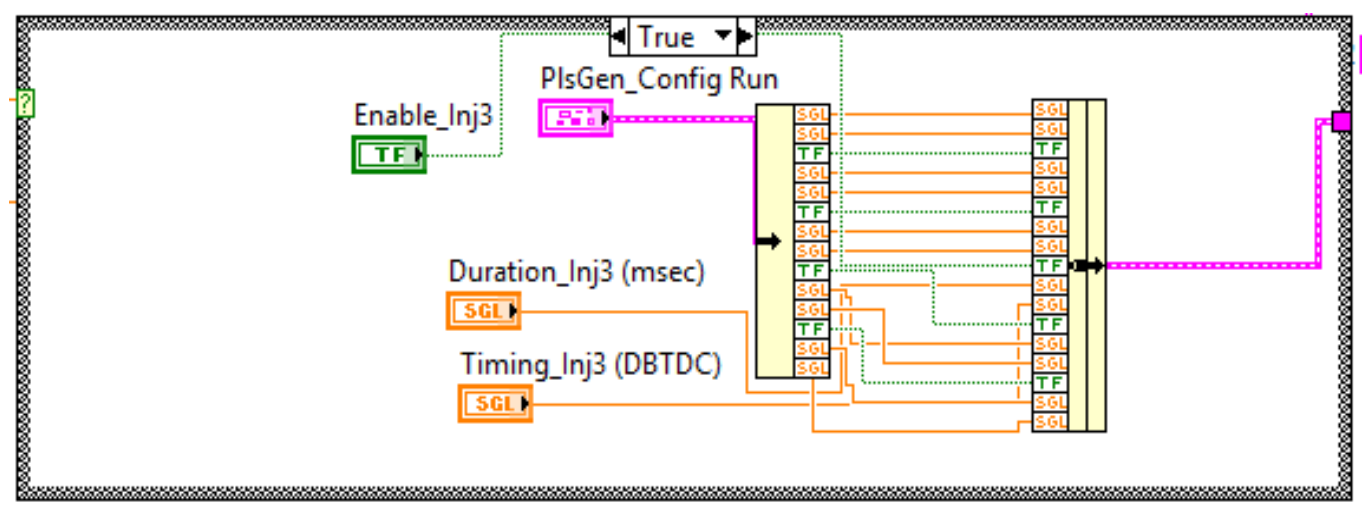

Figure 3-3 Block diagram shows modified injection cluster

The front panel of the speed control loop is shown in Figure 3.4. Except for injection duration, all other parameters including the enable/disable button are controlled manually except injection duration. To minimize the deviation from the desired speed it was necessary to tune the control parameters proportional $(\mathrm{kp})$ and the integral coefficients (Ki). In the experiments it was found that engine maintained the desired speed with less than $0.3 \%$ error when the $\mathrm{Kp}$ and $\mathrm{Ki}$ values were set to be 0.001 and $10^{-5}$, respectively. The millisecond multiple value determines the execution speed of feedback loop. The execution speed of the feedback loop in the RT controller is greater than that of engine and this will lead to instability in controlling the engine. Therefore, synchronization was made through determining the execution speed of algorithm as shown in calculation: 
Execution speed of algorithm $(m s)=\left[\frac{\text { Engine speed }(r p m)}{2 \times 60 \times 1000}\right]^{-1}$

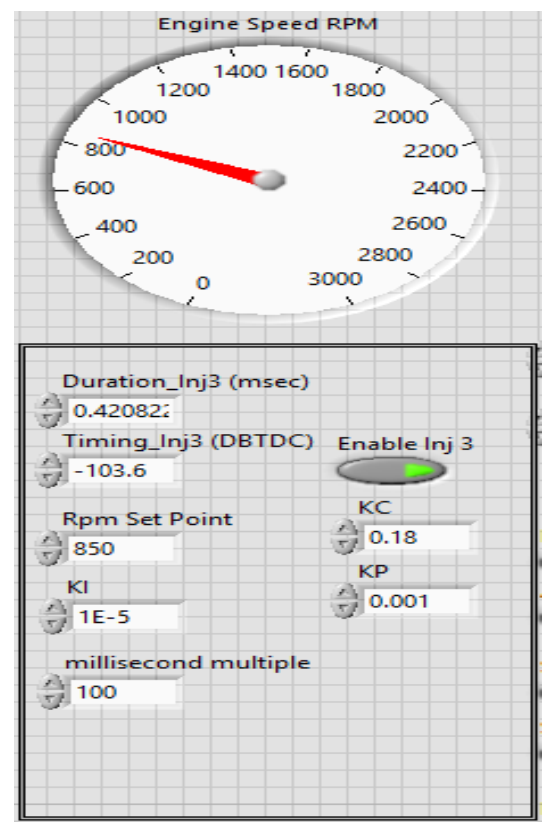

Figure 3-4 Front panel of speed control program

The block diagram for the speed control feedback loop as well as the algorithm of the sub-VI for the disabled and enabled conditions are shown in Figure 3.5. When cranking the engine or when the speed was below $700 \mathrm{rpm}$ speed control was kept disabled. Because as was mentioned above, the $3^{\text {rd }}$ injection used in the algorithm was removed from the run configuration which is not active until the engine reaches the transition speed. When it is enabled, the $3^{\text {rd }}$ injection starts injecting with initial injection duration of $0.3 \mathrm{~ms}$ then varies to maintain the desired idle speed. Here the shift registers were used for error accumulation to calculate the integral response to eliminate the offset. 


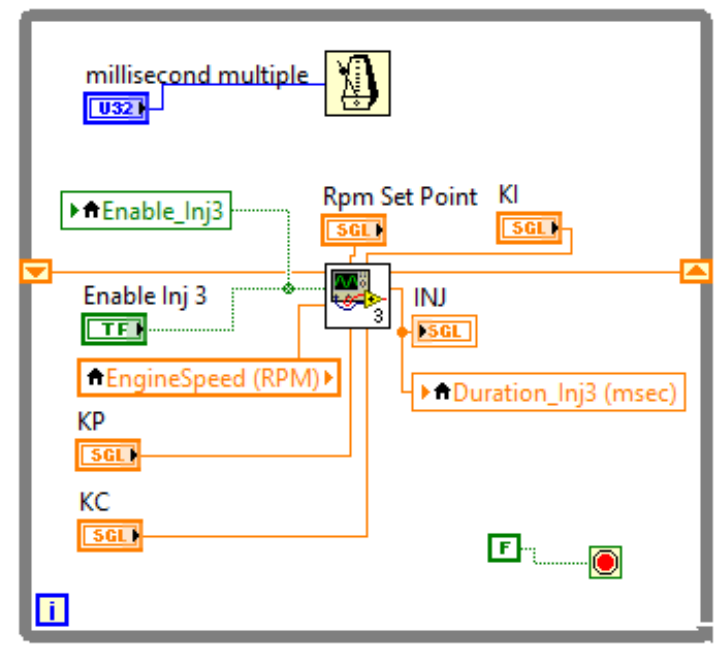

(a)

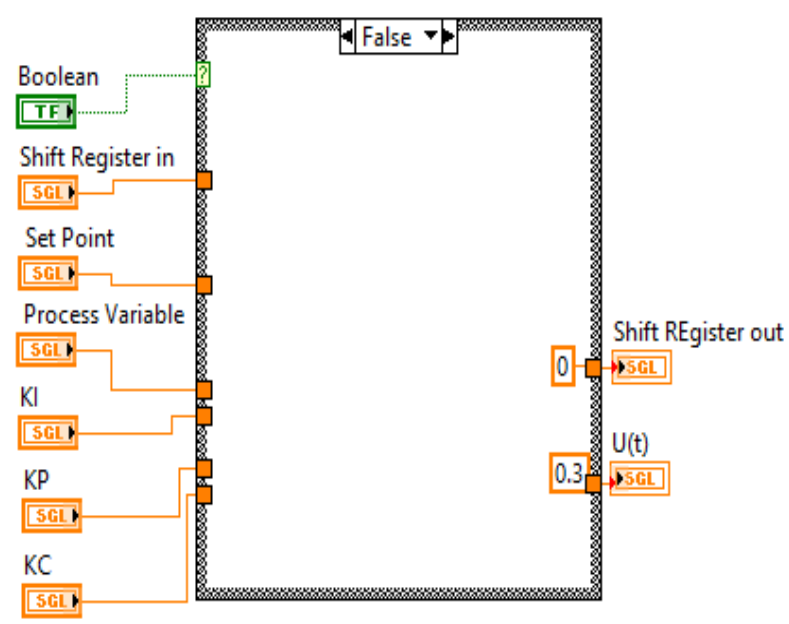

(a)

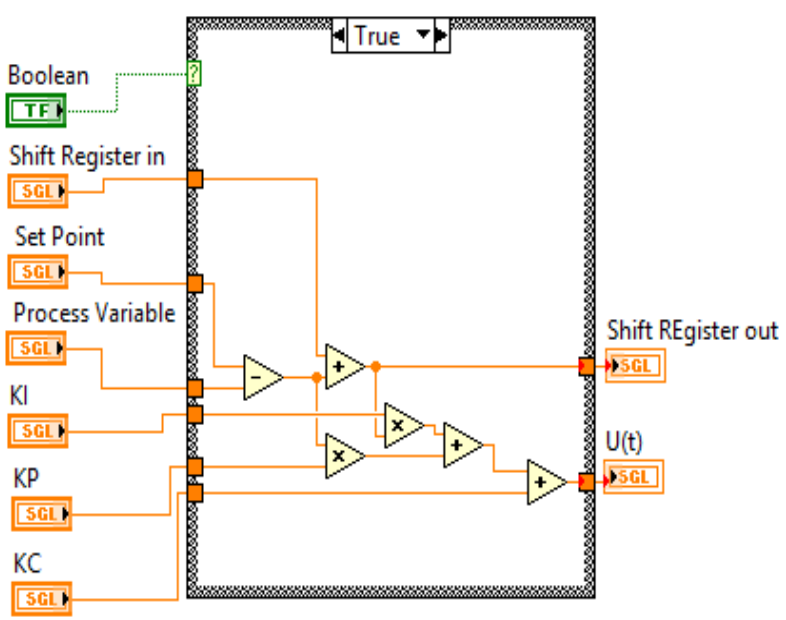

(b)

Figure 3-5 Block diagrams of Speed control algorithm. (a) main algorithm, (b) sub vi for disabled configuration (c) sub vi for enabled configuration

In our engine control program, along with speed control, other crucial engine parameters including rail pressure and throttle position were controlled with PI based feedback loops. It is necessary to introduce the basics of PI control. 
P-only control exclusively uses the correction factor that is proportional to the error $\mathrm{e}(\mathrm{t})$ as shown in equation:

$$
e(t)=S P-P V
$$

$\mathrm{SP}$ is the setpoint value at which the process variable (PV) is desired to be kept. e $(\mathrm{t})$ is the discrepancy between these two values at a time t. Control output $u(t)$ is the response of the actuator to keep PV stable and it is calculated by multiplying e $(\mathrm{t})$ with the process specific value of $\mathrm{k}_{\mathrm{p}}$ in other words proportional gain as shown in equation:

$$
u(t)=k_{p} \times e(t)
$$

In Figure 3.6 a P-only control circuit is demonstrated.

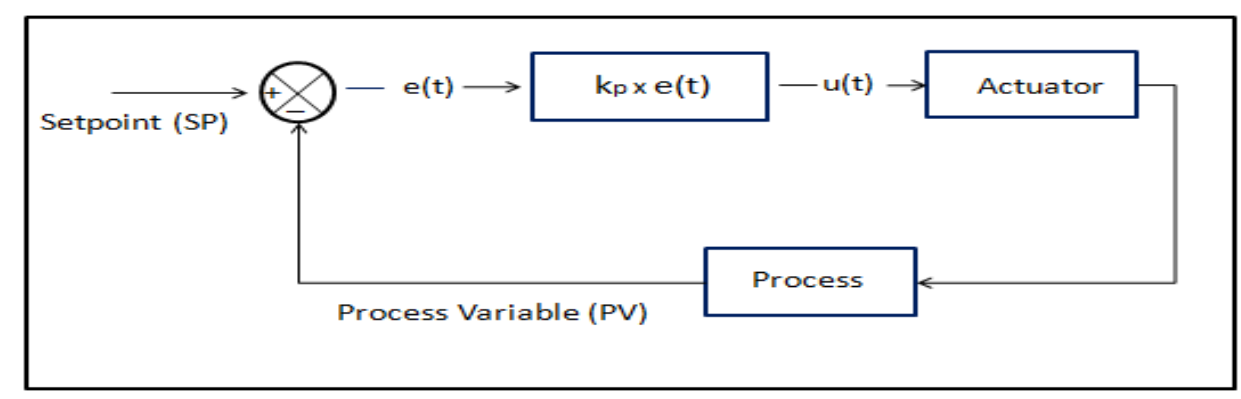

Figure 3-6 P-only algorithm circuit

Although P-only control is useful in many case it is almost always subject to offset. To eliminate the constant error e(t), integral gain should be added to the proportional gain hence P control transforms into proportional-Integral (PI) control. Integral gain is basically multiplication of the Integral factor $k_{i}$ with the accumulated error as shown in equation:

$$
I=k_{i} x \int e(t) \cdot d t
$$

Therefore, the control output $\mathrm{u}(\mathrm{t})$ for the PI configuration is calculated according to equation: 


$$
u(t)=k_{p} x e(t)+k_{i} x \int e(t) \cdot d t
$$

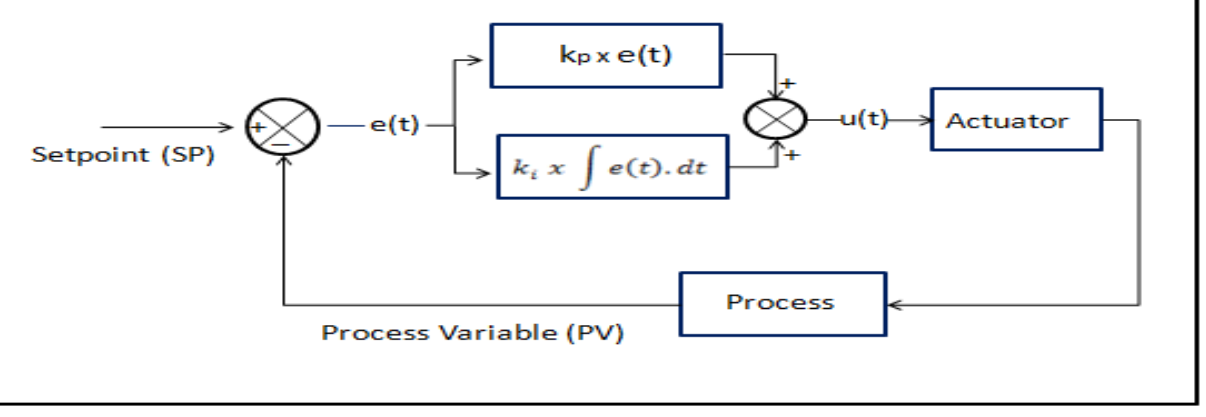

Figure 3-7 PI control-loop mechanism

In the speed control algorithm used for our engine, the process variable and the control output were engine speed and duration of injection, respectively. The fuel injector was the actuator or final control element. Three different set points used for the experiments were 850,1100 and $1200 \mathrm{rpm}$.

Rail pressure was also controlled with a PI feedback loop as shown in Figure 3.8. The only difference was that the algorithm, as shown in Figure 3.9, included pulse-widthmodulation (PWM) generation codes along with PI loop. Because, unlike the fuel injectors the fuel metering valve requires a PWM signal. Generating a PWM signal using a digital I/O module requires higher execution speed hence the control loop was placed in the FPGA VI rather than in RT. As with speed control, to maintain injection pressure at the desired level, the proportional and integral coefficients needed to be tuned. It was found that throughout the entire experiments rail pressure was controlled with less than $0.4 \%$ of error with fine-tuning. However, tuning needed to be redone each time the engine was restarted. In the rail pressure control algorithm, the process variable was the output of the calibrated 
rail pressure sensor, and since the fuel metering valve was the final control element, the control output was the duty cycle of the PWM signal.

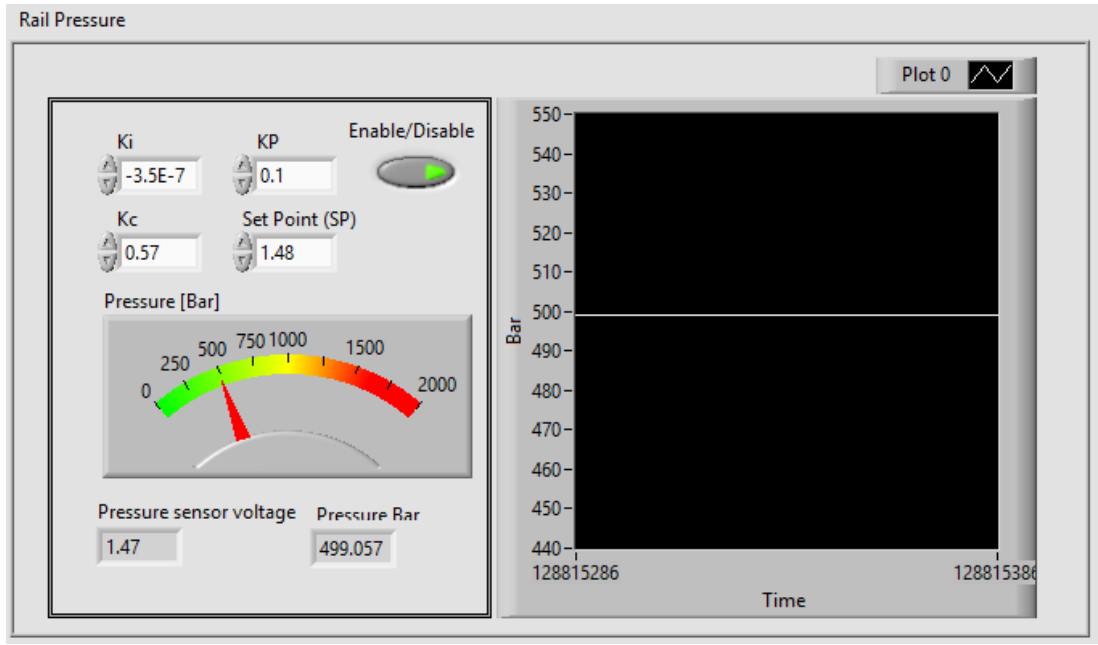

Figure 3-8 Front panel of rail pressure control program

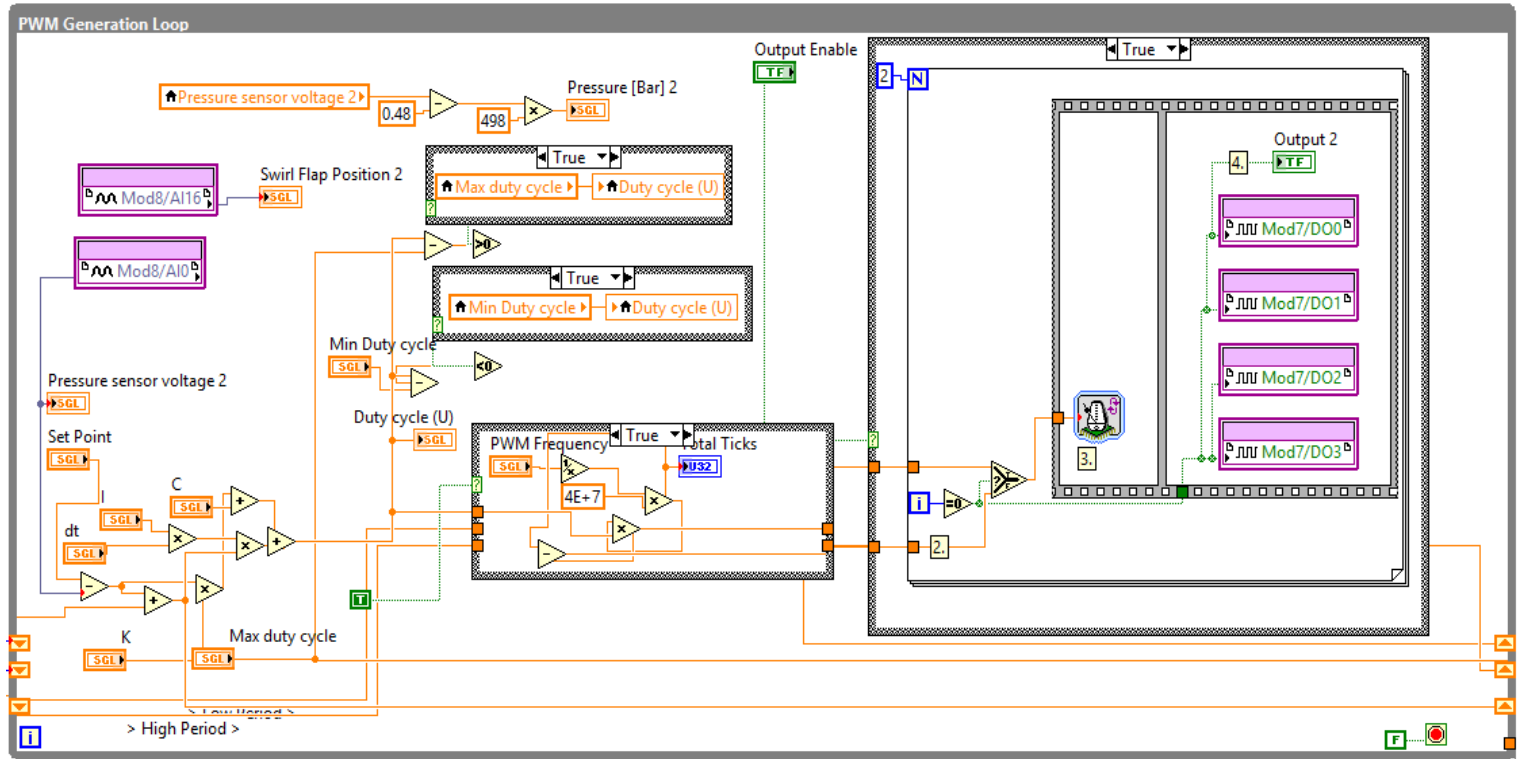

Figure 3-9 Block diagram of rail pressure control and PWM signal generator 
For the throttle plate control a PWM generation loop was also programmed in the FPGA, as shown in Figure 3.10. As with the fuel metering valve, the throttle plate actuator is compatible with a PWM signal. The PI algorithm was placed in RT and the programmatically varied duty cycle that was converted to a PWM signal in FPGA. The essential purpose of controlling the throttle position was altering manifold absolute pressure (MAP). In the algorithm, the process variable was the signal output of the throttle position sensor. Since the sensor was not calibrated, the voltage output used as the set point and the duty cycle of the throttle plate actuator was the control output. Throttle plate was controlled with less than $0.1 \%$ error with fine tuning of PI coefficients. Kp and Ki were determined to be 0.99 and $7 \times 10^{-6}$, respectively. The MAP sensor was calibrated using a precision bourdon tube absolute pressure meter which was then correlated with the output read by the CAS software for different engine operating conditions and throttle plate positions. However, for future work it would be wiser to replace the throttle plate sensor output with a MAP sensor output in the same algorithm while keeping the throttle plate actuator as the final control element to directly control the MAP.

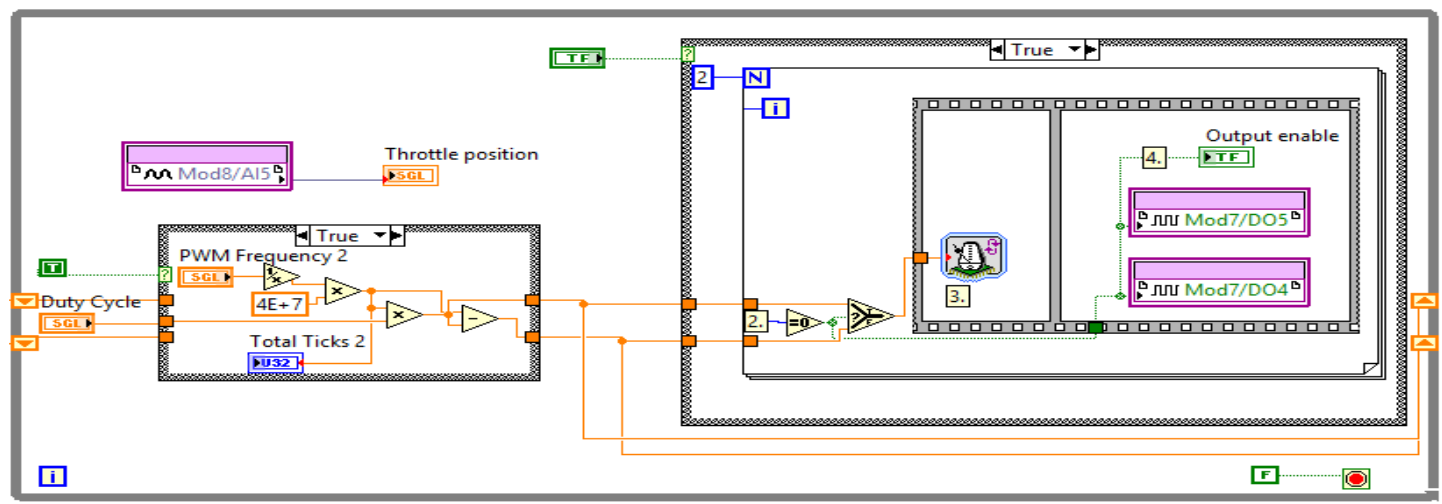

(a) 


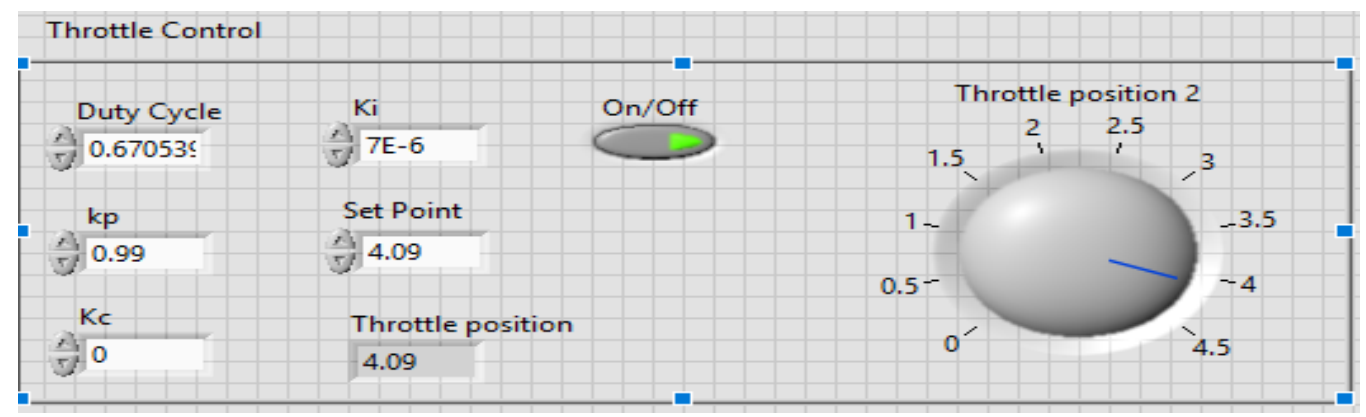

Figure 3.10 Throttle Plate Control. (a) Block diagram, (b) front panel

To record the engine operating parameters as well as $\mathrm{NO}_{\mathrm{x}}$ and $\mathrm{CO}_{2}$ emissions, a data acquisition algorithm was developed in the RT VI. Data, sampled from over 100 engine cycles was averaged to improve the accuracy of the measurements and was recorded in a TDMS file. The test name can be changed for different operating conditions while the $\mathrm{RT}$ is running. This makes grouping the data easier. However, the main file needs to be named before running RT and if it is necessary to rename the file it should be stopped and run again after changing data file name.

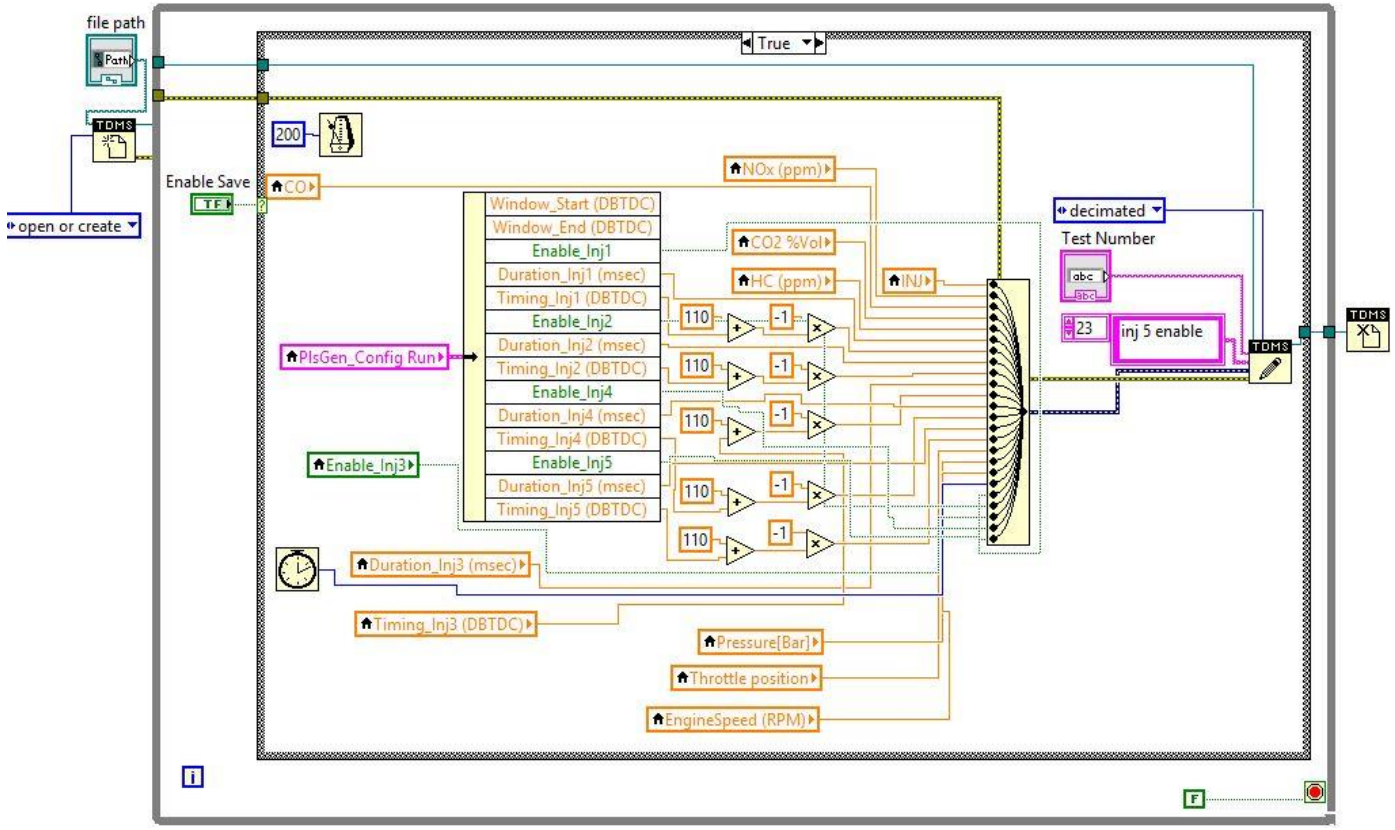

Figure 3-11 Block diagram of data acquisition loop in LabVIEW RT 


\section{Chapter 4: Results and Discussion}

Determining the baseline injection parameters that represent the engine's production idle operation was the first step in the experiments, and as mentioned before, the injection strategies of the Chevrolet Cruze engine were desired. These include such parameters as the number of injection, injection duration and the separation between each injection. Since we were not able to measure the crank angle phasing of the injections from the Cruze engine, a variety of different injection phasings were studied in the test engine to find the timing that yielded optimum exhaust temperature, emissions and engine stability. Figure 4.1 shows these results, where the $\mathrm{x}$-axis is the crank angle with 0 degree being TDC of compression. The figure shows the relative insensitivity of the exhaust temperature, $\mathrm{HC}$ emissions, and COV of IMEP to this phasing. The HC measurements for this figure only were NDIR based not FID based. The $\mathrm{NO}_{\mathrm{x}}$ emissions, however are seen to decrease as injection was retarded.

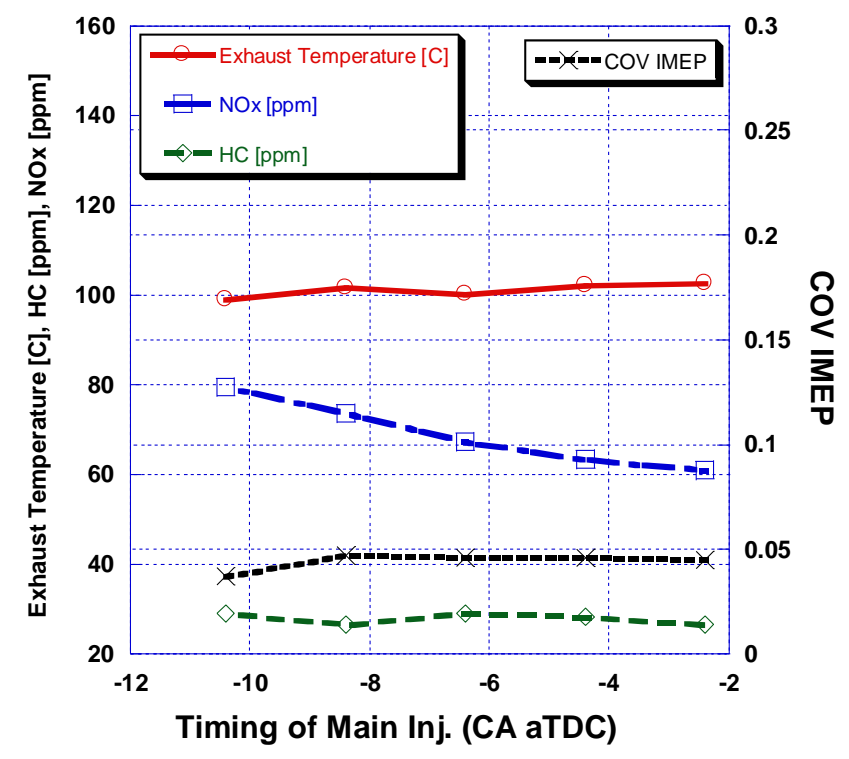


Figure 4-1 Effect of SOI baseline injection strategy without post-injection on exhaust temperature, cov of IMEP and emissions ( $850 \mathrm{rpm}, 500$ bar of injection pressure, WOT)

A start of injection (SOI) of $6.5^{\circ} \mathrm{bTDC}$ was chosen arbitrarily in the middle of the range investigated and the $3^{\text {rd }}$ injection was retarded because it was found that it aided the combustion of the $4^{\text {th }}$ injection, thus, improving the engine stability.

For the given baseline injection strategy without post-injection for an idle speed of $850 \mathrm{rpm}$ and injection pressure of 500 bar and WOT, exhaust temperature was measured to be $105^{\circ} \mathrm{C}$. This was approximately half of the aftertreatment systems' light off temperature.

The effect of the amount of fuel injected in the $4^{\text {th }}$ injection was investigated, with the results shown in Figure 4.2. The exhaust temperature increased, and $\mathrm{NO}_{\mathrm{x}}$ emissions decreased as more fuel was added; however, the relatively small fixed injection duration of $0.3 \mathrm{~ms}$, corresponding to $0.52 \mathrm{mg}$ of fuel mass, was used in order to maintain the necessary low idle speed for all of the operating conditions investigated in this study.

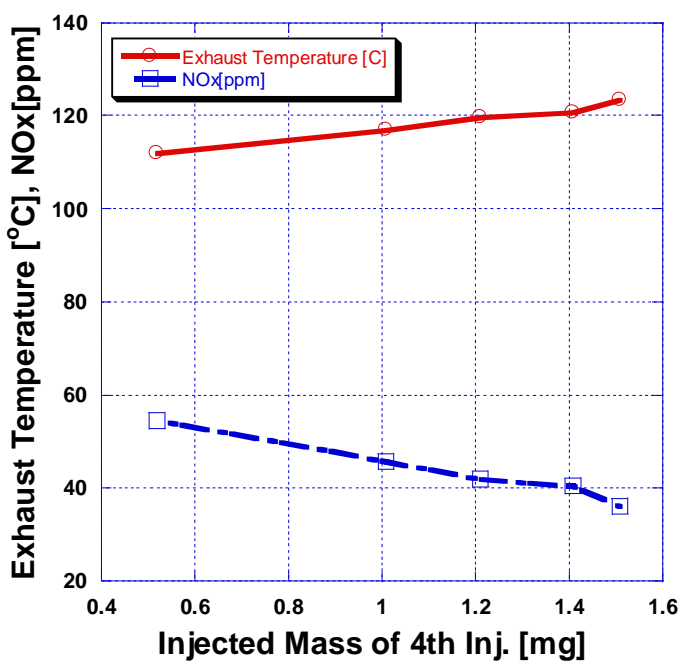


Figure 4-2 Exhaust temperature and $\mathrm{NO}_{\mathrm{x}}$ vs. injected fuel mass of $4^{\text {th }}$ injection at $25^{\circ} \mathrm{CA}$ aTDC at $850 \mathrm{rpm}, 500$ bar

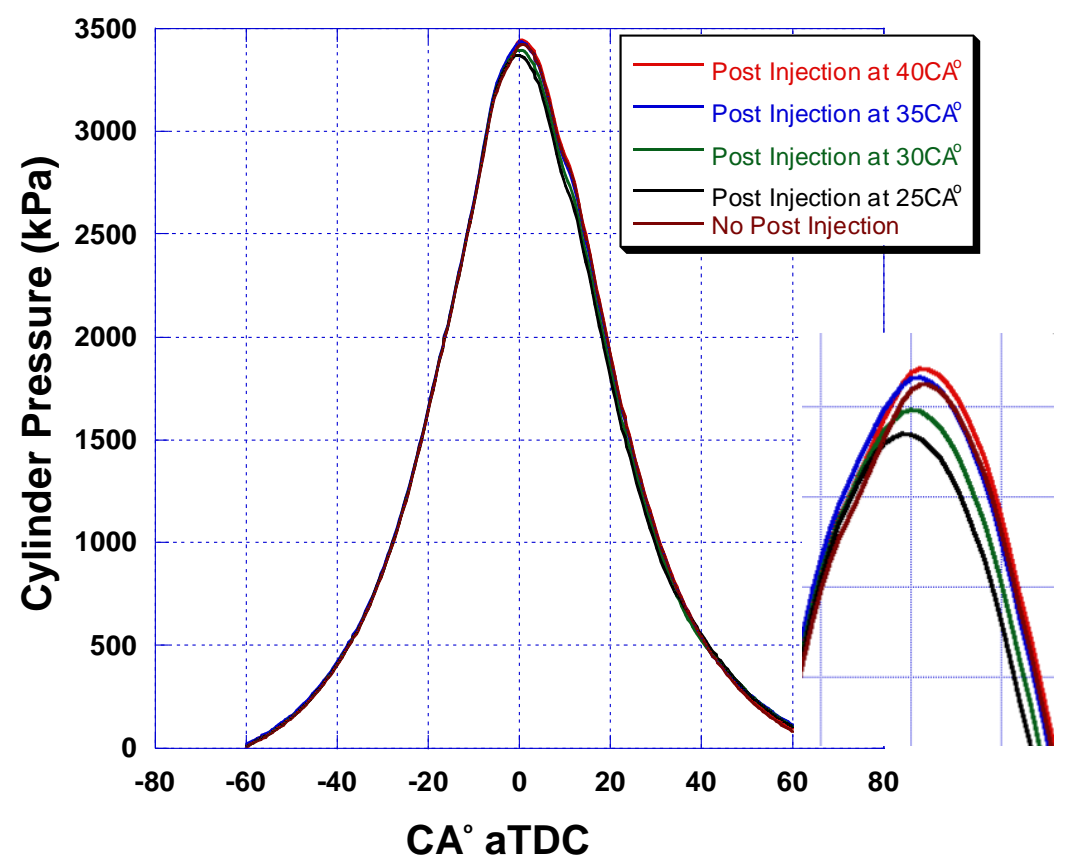

Figure 4-3 In-cylinder pressure vs. SOI of $4^{\text {th }}$ injection at $1100 \mathrm{rpm}, 500 \mathrm{bar}$

Figure 4.3 shows the effect of the injection timing of post-injection between $25^{\circ}$ and $40^{\circ}$ on in-cylinder pressure along with the pressure trace for the no post-injection case for $1100 \mathrm{rpm}$ and 500 bar of injection pressure. It was observed that the contribution of the injected fuel to the IMEP decreased as the $4^{\text {th }}$ injection was retarded more, and the duration of the main injection increased automatically to maintain a stable idle speed this resulted in higher peak pressure. The pressure for the post-injection cases rose slightly faster than the no-post-injection case starting around $5^{\circ}$ bTDC, perhaps because of hotter exhaust residual enhancing fuel reaction rates in the case of post-injection. 
The throttling effect was studied in the range that varied from wide open throttle (WOT) with MAP of $101 \mathrm{kPa}$ to the degree that in some operating conditions resulted in MAP as low as $52 \mathrm{kPa}$. Beyond certain MAP values the engine was not able to sustain stable idle speed depending on the operating conditions. The amount of throttling had a significant effect on in-cylinder pressure. Figure 4.4 shows cylinder pressure vs. crank angle for different values from WOT to heavily throttled case with MAP of $52 \mathrm{kPa}$. Peak pressure showed a downward trend with decreasing MAP. However, IMEPs stayed nearly the same for the different MAP values.

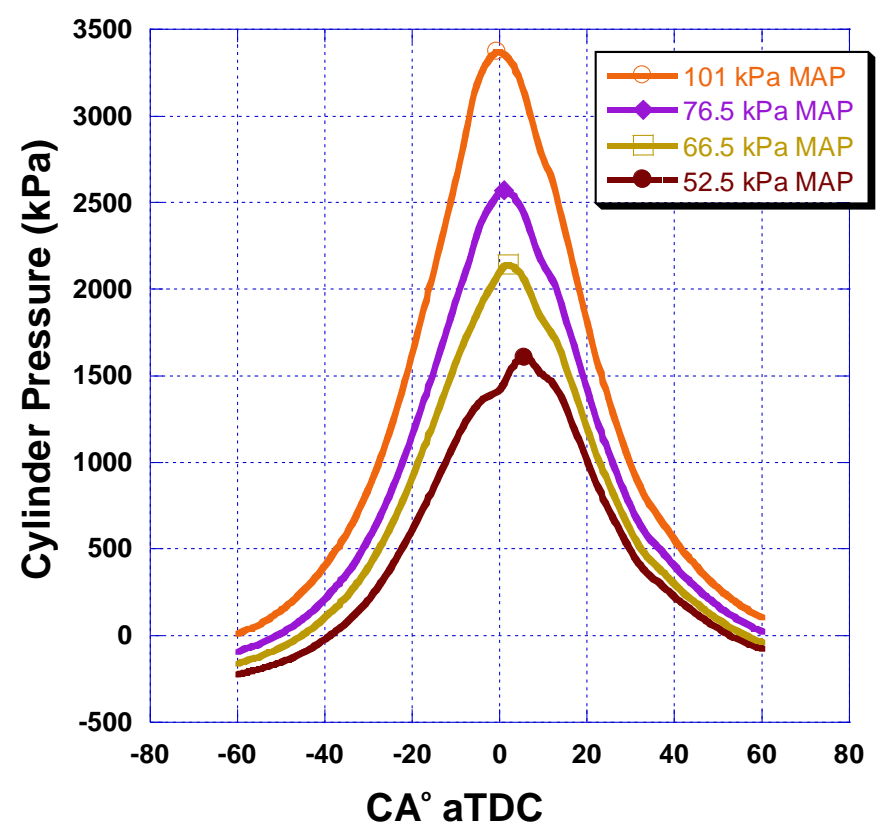

Figure 4-4 . In-cylinder pressure vs. crank angle showing the effect of throttling on incylinder pressure (1100 rpm, 500 bar injection pressure, post-injection SOI of $25^{\circ} \mathrm{CA}$ aTDC). 
Figure 4.5 shows the gross and net IMEP derived from the pressure traces averaged over 100 cycles. At idle conditions net IMEP can be practically considered as equal to the friction mean effective pressure due to lack of brake power. Thus, it was expected to have approximately the same net IMEP value for different MAP values which is mostly the case except for the lowest MAP value and the reason for which is uncertain. The main feature of interest is that net IMEP is relatively constant even though cylinder pressure was very different for the different levels of throttling. It is also of interest because there is very little idling IMEP data in the literature for modern light-duty Diesels.

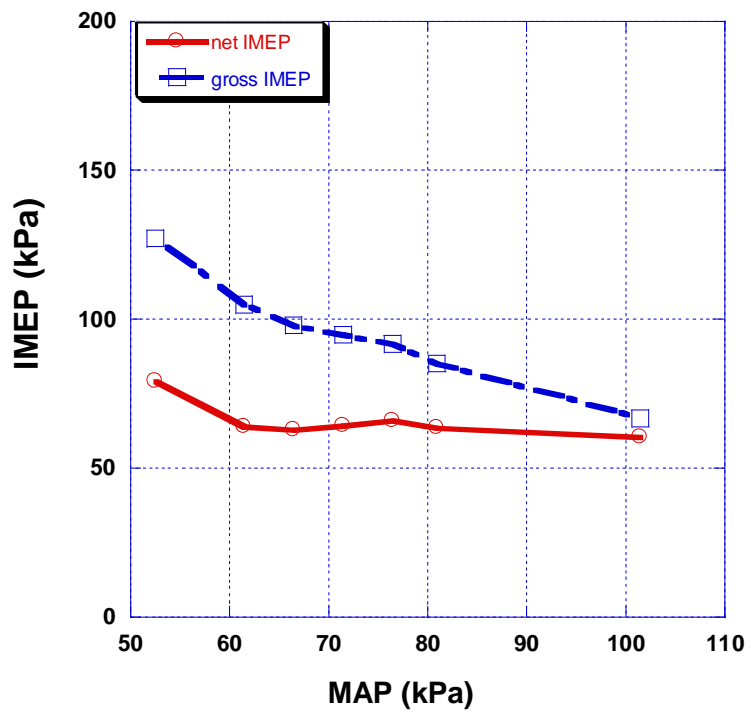

Figure 4-5 Gross and net IMEP vs. MAP (1100 rpm, 500bar injection pressure)

\section{BAR InJeCtion Pressure}

Figure 4.6 shows exhaust temperature change with the MAP and the SOI of postinjection for three idle speed of 850, 1100 and $1200 \mathrm{rpm}$. They were chosen close together to check both for data consistency and to check whether there were any strong speed sensitivities. The injection pressure was 500 bar. 
Heavy throttling along with post injection led to a rise in exhaust temperature by 80 to $100{ }^{\circ} \mathrm{C}$. The same throttle position settings were used for all three idle speeds however corresponding MAPs, that is measured by the MAP sensor, varied for each speed. It was possible to achieve lower MAP values at the higher idle speeds of 1100 and $1200 \mathrm{rpm}$ compared to $850 \mathrm{rpm}$.

Two of the primary questions I sought to investigate going into this research were: 1) how far I could retard post-injections and still have nearly complete combustion, and 2) whether retarding post-injection would lead to higher exhaust temperatures, the reasoning being that injection and therefore combustion later into the expansion stroke would result in less expansion cooling, giving higher exhaust temperatures

Results showed that the SOI of post injection unexpectedly did not have a significant effect on exhaust temperature. In fact, beyond nearly SOI of $25^{\circ} \mathrm{CA}$ temperature showed a declining trend and for this reason post-injections beyond $40-45^{\circ} \mathrm{CA}$ aTDC were not investigated.

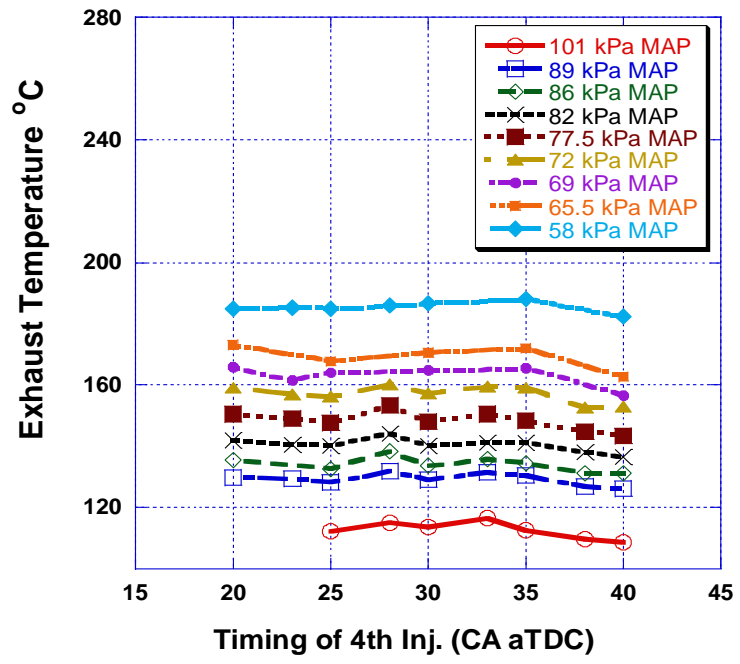

(a) 


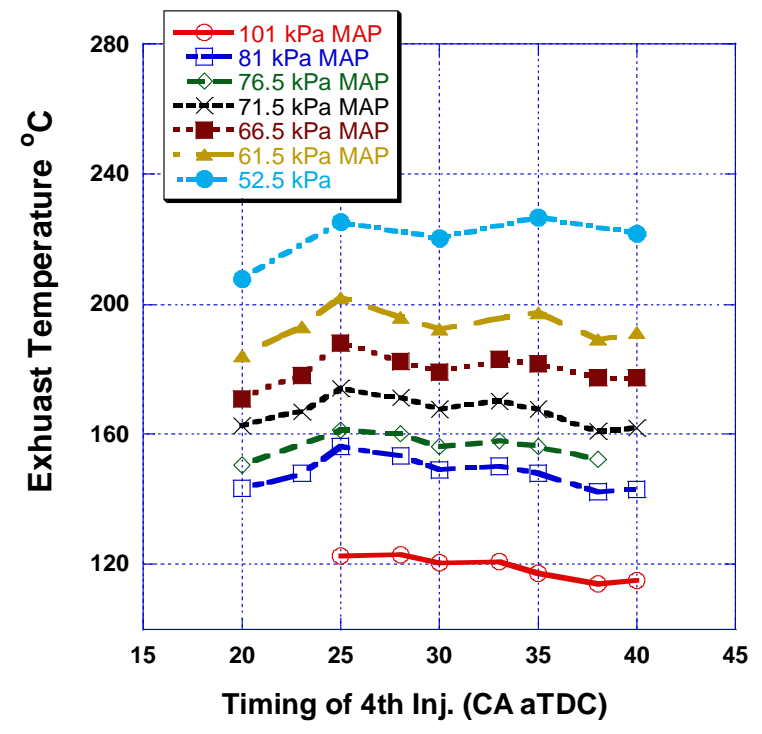

(b)

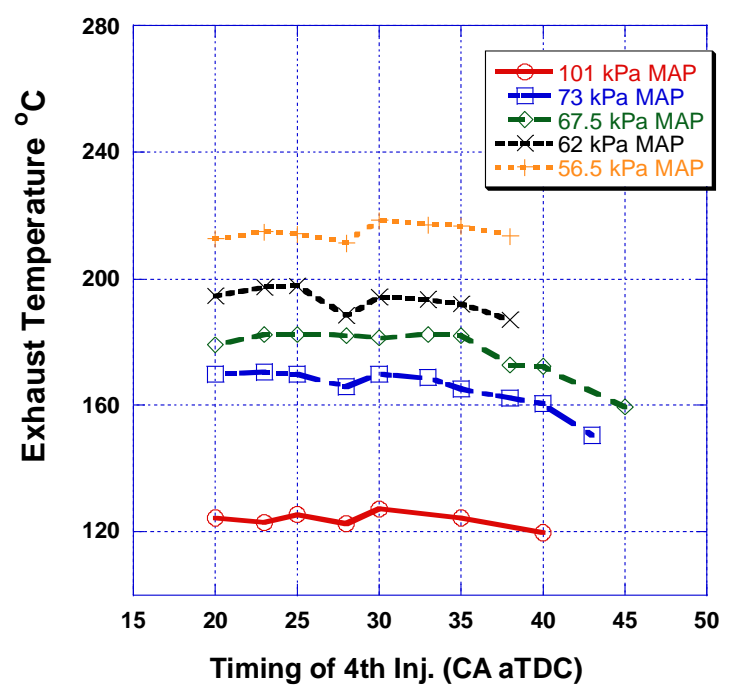

(c)

Figure 4-6 Engine-out exhaust temperature vs. SOI for the $4^{\text {th }}$ injection which is preceded by one pre-injection, a main injection and an early post-injection. The temperatures are given for various MAPs according to a degree of throttling and for an injection pressure of $500 \mathrm{bar}$, (a) $850 \mathrm{rpm}$, (b) $1100 \mathrm{rpm}$, (c) $1200 \mathrm{rpm}$. 
As shown in the Figure 4.7, the $\mathrm{HC}$ emissions similar to exhaust temperature showed a subtle dependence on engine speed and roughly doubled as the MAP was reduced from atmospheric pressure to approximately $50 \mathrm{kPa}$. Near $25-30^{\circ} \mathrm{CA}$ of injection timing of the $4^{\text {th }}$ injection the $\mathrm{HC}$ emissions had a local dip and beyond that point an upward trend was observed. The high $\mathrm{HC}$ and low exhaust temperature in the range of $30-45^{\circ} \mathrm{CA}$ SOI of the $4^{\text {th }}$ can be attributed to inefficient combustion of the post-injection fuel. Particulate matter emissions were not measured; they, of course, are an additional path for fuel carbon.

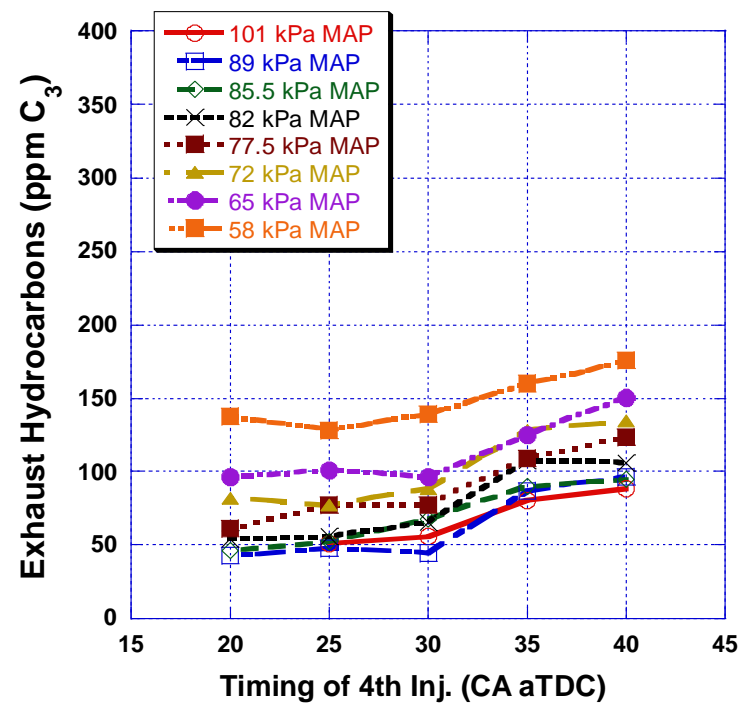

(a) 


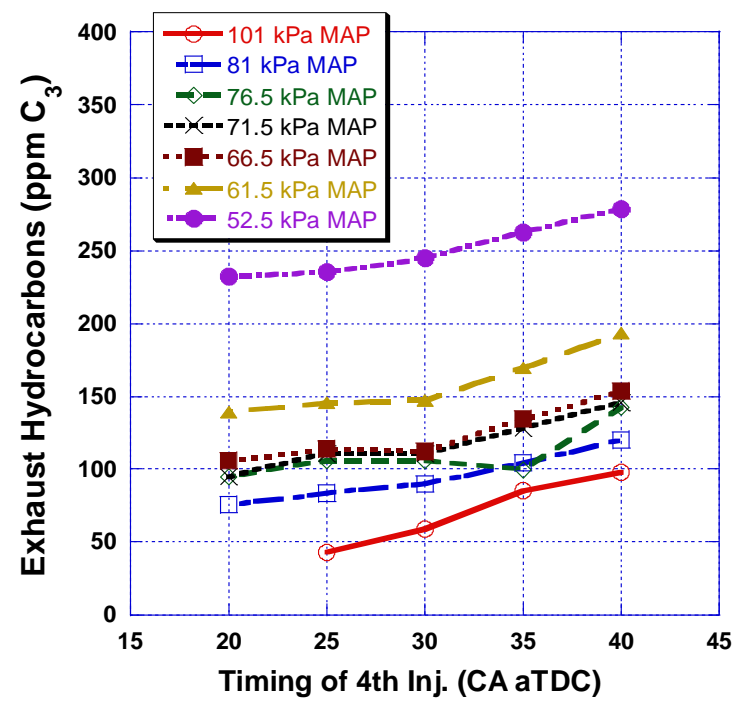

(b)

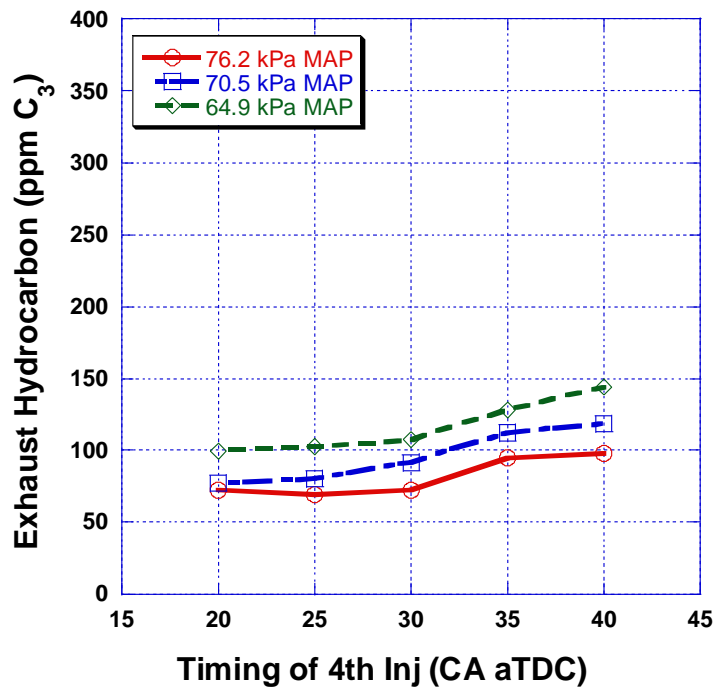

(c)

Figure 4-7 Engine out HC emissions vs. SOI of $4^{\text {th }}$ injection. The results are plotted parametrically for various MAPs (throttle position) and injection pressure of 500 bar. (a) $850 \mathrm{rpm}$, (b) $1100 \mathrm{rpm}$, (c) $1200 \mathrm{rpm}$ 
In Figure $4.8 \mathrm{NO}_{\mathrm{x}}$ emission showed a trend similar to $\mathrm{HC}$ emission. Decreases in MAPs caused higher $\mathrm{NO}_{\mathrm{x}}$ emission, roughly doubled between WOT to heaviest throttling case. Retarding the SOI of post-injection led to an increase in NOx emissions by up to $20 \%$, however it was less significant compared to the effect of throttling. It was also interesting to note that there were some reproducible variations in NOx for the SOI of the $4^{\text {th }}$ injection between 25 and $30^{\circ} \mathrm{CA}$ aTDC at $1100 \mathrm{rpm}$. This behavior was more evident at higher MAP values.

As mentioned in Chapter 3 the duration of the main injection $\left(2^{\text {nd }}\right.$ injection) was varied to maintain idle speed. In Figure 4.8 the duration of the main injection is shown as a function of the SOI of the post-injection. The variations in $\mathrm{NO}_{\mathrm{x}}$ seen in Figure 4.7 correlate with the main injection duration as the higher injection duration led to an increase in $\mathrm{NO}_{\mathrm{x}}$ emissions. This is expected because the SOI of the main injection was $6.5^{\circ} \mathrm{bTDC}$ and a greater amount of fuel injected bTDC increases the peak pressure hence, the incylinder temperature. However, it is not known why the fuel requirement for a stable idle was so irregularly sensitive to the post-injection SOI timing over such a short SOI timing interval.

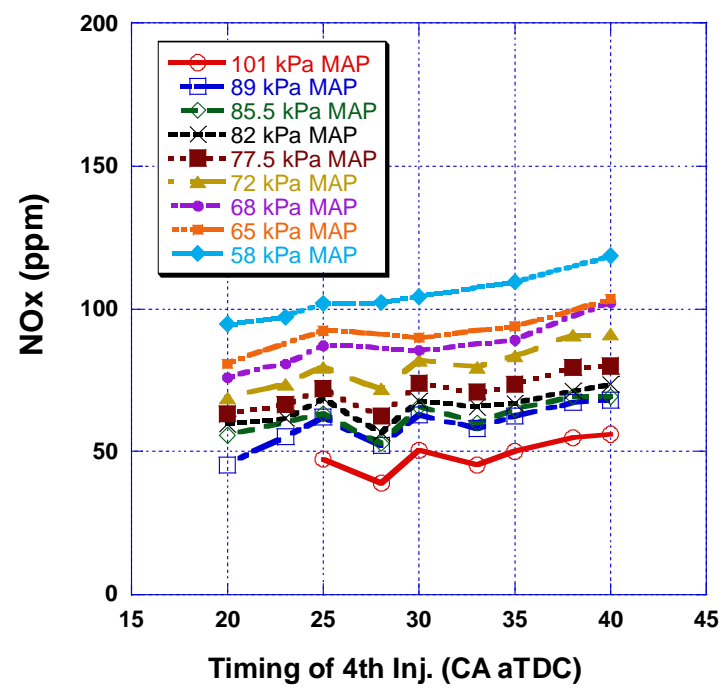


(a)

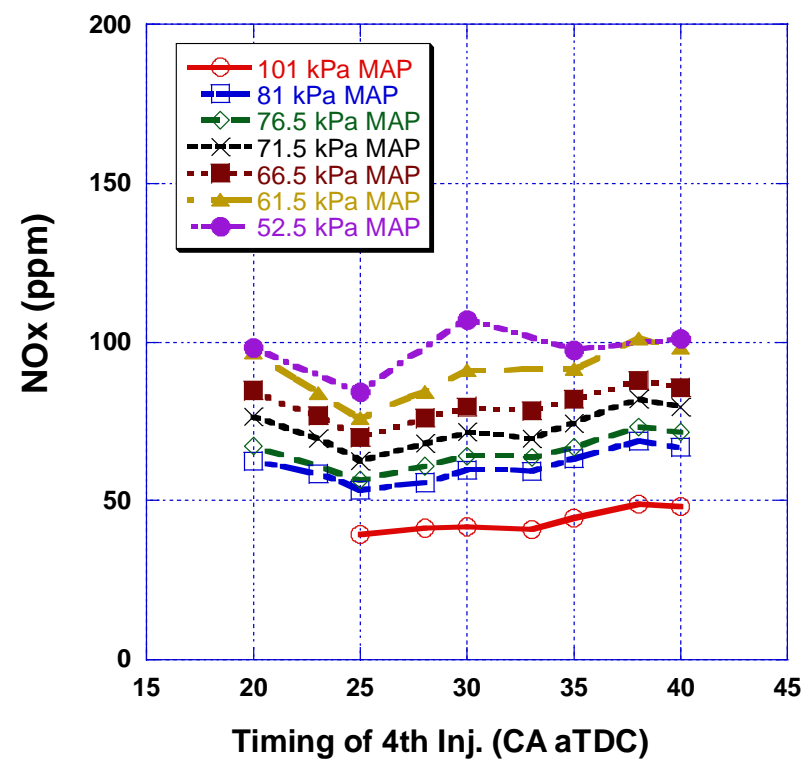

(b)

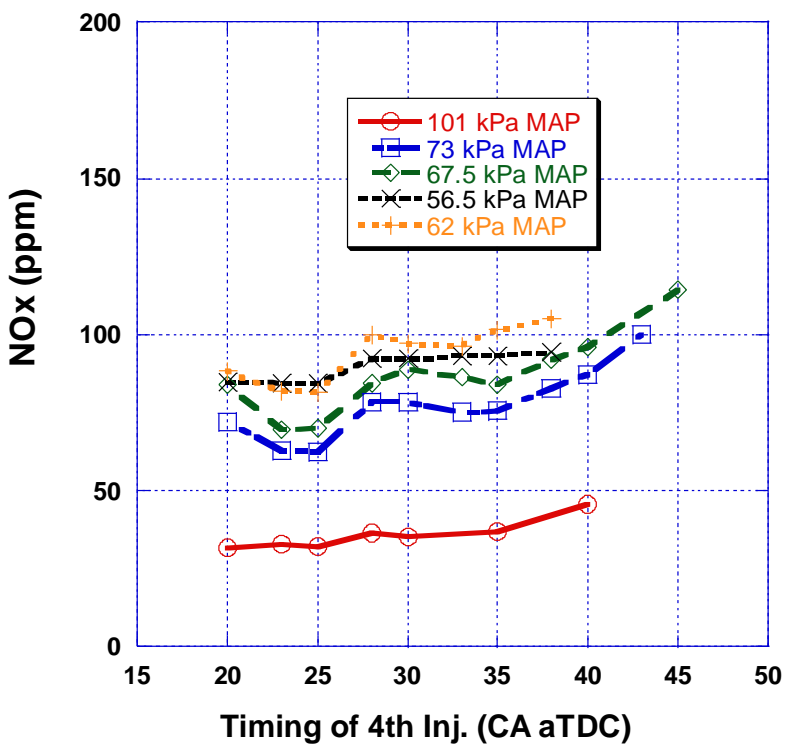

(c) 
Figure 4-8 Engine-out $\mathrm{NO}_{\mathrm{x}}$ emissions vs SOI of $4^{\text {th }}$ injection. The results are plotted parametrically for MAPs (degree of throttling) and for an injection pressure of 500 bar, (a) $850 \mathrm{rpm}$, (b) $1100 \mathrm{rpm}$, (c) $1200 \mathrm{rpm}$

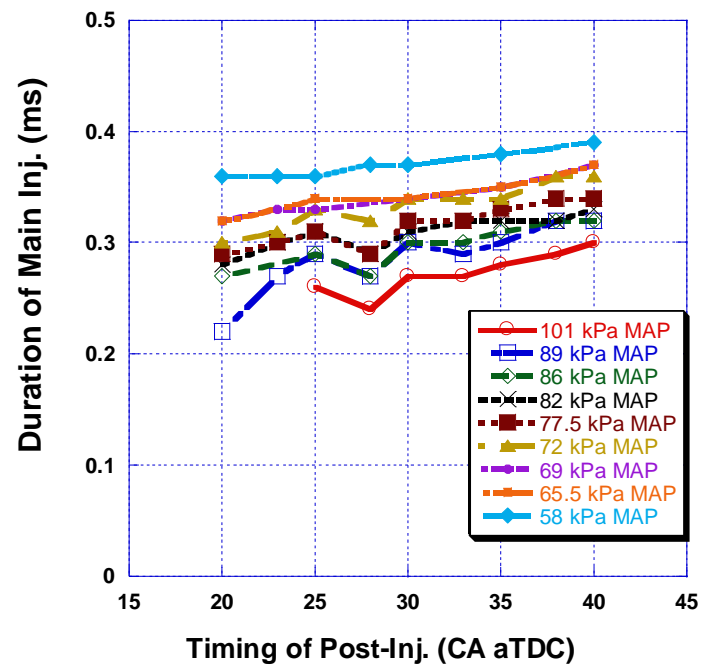

Figure 4-9 Duration of main injection vs. post- injection timing, $850 \mathrm{rpm}, 500$ bar of injection pressure

Figure 4.10 shows the effect of throttling on exhaust temperature for the baseline conditions without post injection for $850 \mathrm{rpm}$ and $1100 \mathrm{rpm}$ and for 500 bar of injection pressure. Exhaust temperature linearly increased with decrease in MAPs for both engine speeds, however the slope was steeper for the higher speeds. 


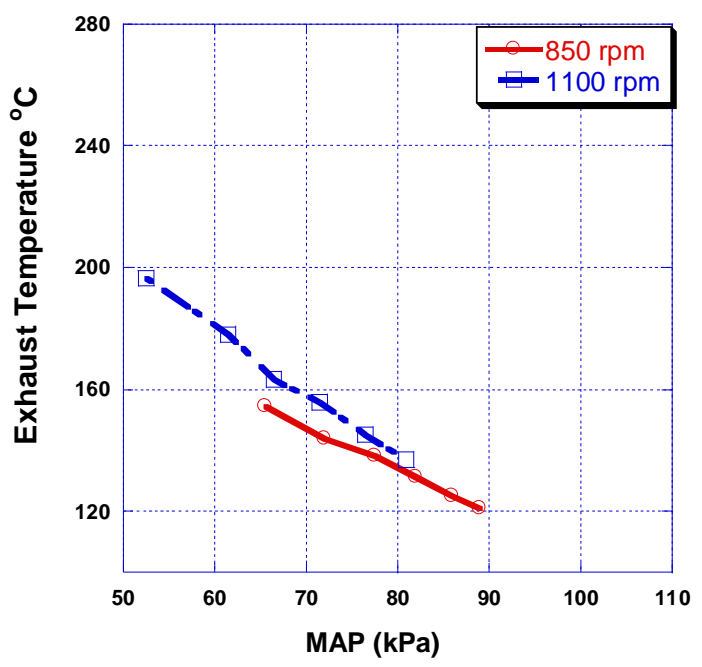

Figure 4-10 Exhaust temperature vs. MAPs for baseline injection strategy with no post injection. $850 \mathrm{rpm}, 1100 \mathrm{rpm}, 500$ bar injection pressure

\section{Bar Injection Pressure}

Figure 4.11 shows exhaust temperature for the 800 bar injection pressure at idle speed of 850 and $1100 \mathrm{rpm}$. For both engine speed similar exhaust temperatures were observed for similar MAPs. The trends are also similar to the case for 500 bar injection pressure. However, for the lowest MAP at $54 \mathrm{kPa}$ at $1100 \mathrm{rpm}$ the temperatures are significantly higher for higher injection pressure compared to the $52.5 \mathrm{kPa}$ MAP case at 500 bar injection pressure.

At $850 \mathrm{rpm}$, exhaust temperature showed a downtrend for almost all throttling cases for the SOI of post-injection beyond $25^{\circ} \mathrm{CA}$ while it had stable or increasing trend up to $30^{\circ} \mathrm{CA}$ of post-injection timing at $1100 \mathrm{rpm}$. This was more evident for heavy throttling cases. This cannot be attributed to the effect of only higher engine speed because for 500 bar injection pressure exhaust temperature declined beyond $25^{\circ} \mathrm{CA}$ at higher speed. 


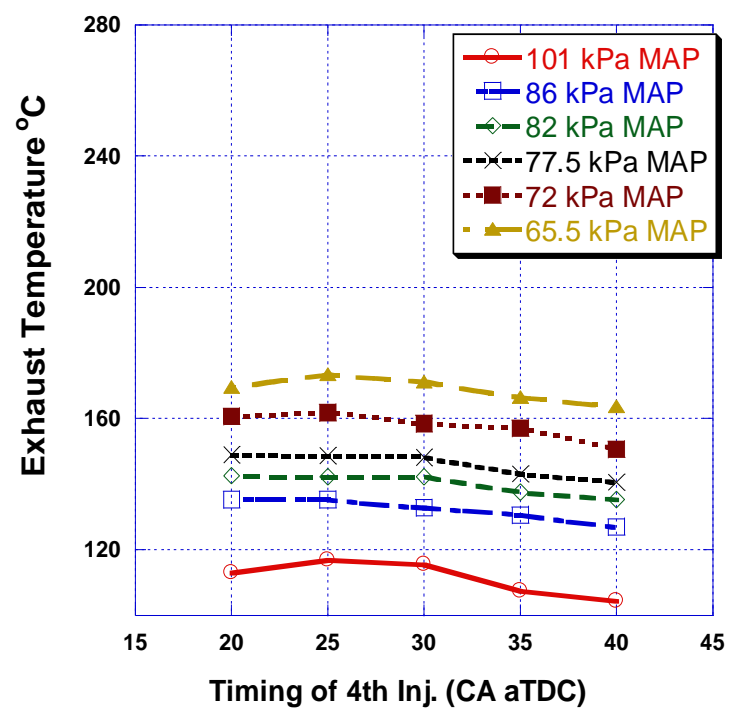

(a)

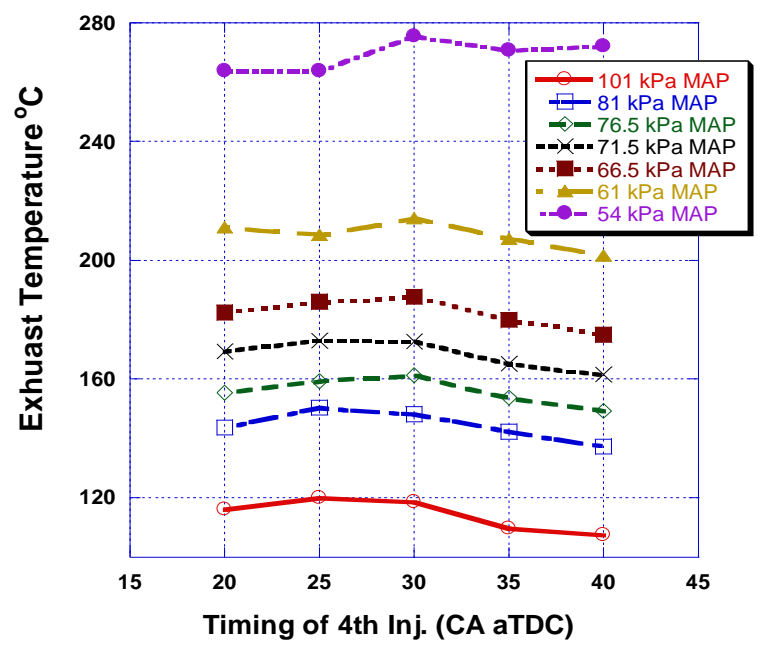

(b)

Figure 4-11 Engine-out exhaust temperature vs. SOI of $4^{\text {th }}$ injection. The results are given for various MAPs (throttle position) and for injection pressure of 800 bar, (a) 850 rpm, (b) $1100 \mathrm{rpm}$ 
Figure 4.12 shows $\mathrm{NO}_{\mathrm{x}}$ emissions at the injection pressure of 800 bar. At higher injection pressure lower engine speeds produced more $\mathrm{NO}_{\mathrm{x}}$ similar to the $\mathrm{NO}_{\mathrm{x}}$ emissions for the injection pressure of 500 bar. It was also observed that at similar MAPs for both injection pressure $\mathrm{NO}_{\mathrm{x}}$ emissions were nearly the same.

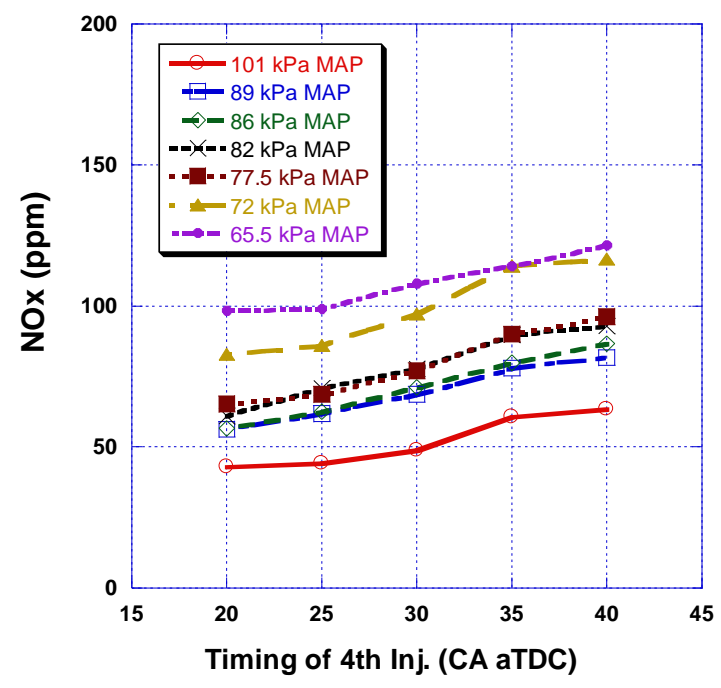

(a) 


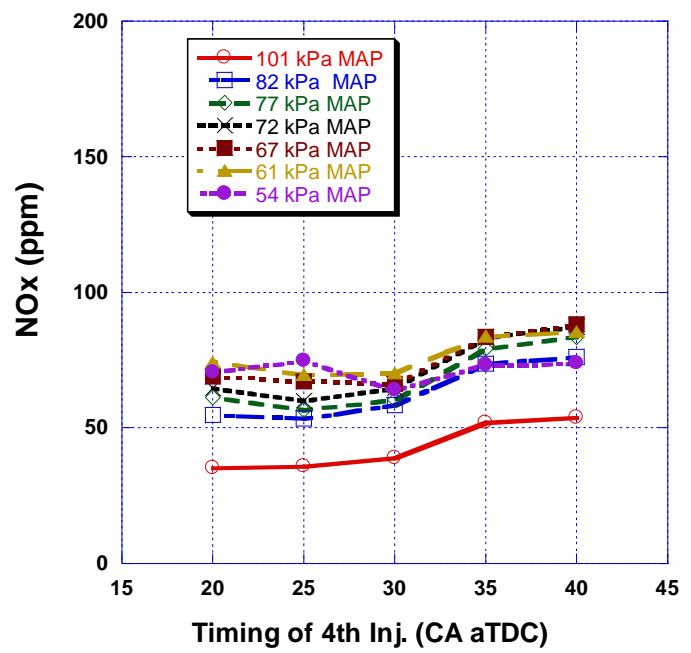

(b)

Figure 4-12 Engine-out $\mathrm{NO}_{\mathrm{x}}$ emission vs. SOI of post-injection. The results are plotted parametrically for various MAPs for an injection pressure of $800 \mathrm{bar}$, (a) $850 \mathrm{rpm}$, (b) 1100 rpm

The injected fuel amount for each injection pressure was obtained by calibrating one of the injectors. It was removed from the cylinder then reconnected to the rail. The engine was motored using the dynamometer and injected fuel mass was collected in a container then measured using a microscale. Calibration results are seen in Figure 4.13. The injected fuel mass changed nonlinearly with injection duration. It is also interesting that the very short injection durations characteristic of an idle condition with multiple injections, the injector was approaching the minimums possible. 


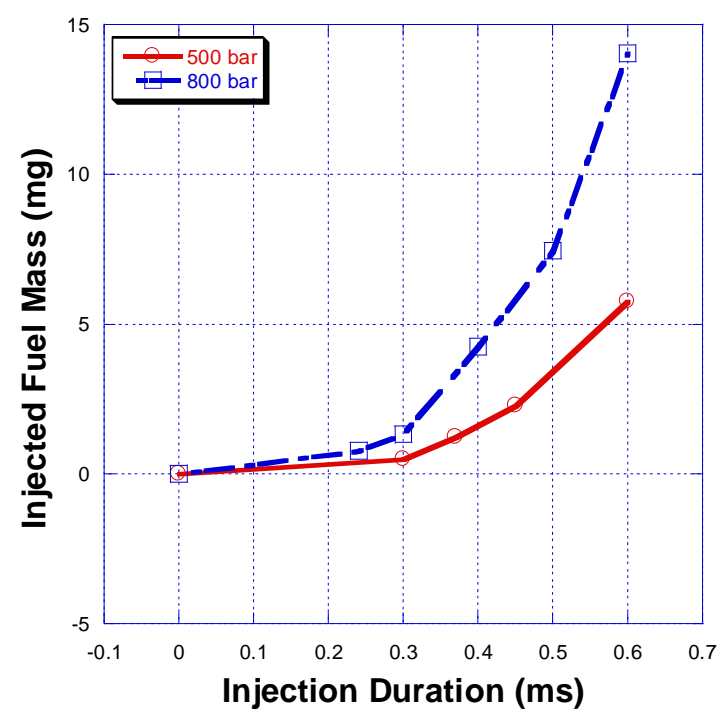

Figure 4-13 Fuel injector calibrations for 500 and 800 bar injection pressure

Figure 4.14 shows the increase in total injected mass with post-injection timing and MAP for injection pressures of 500 and 800 bar at $850 \mathrm{rpm}$ engine speed. The horizontal line represents the amount of fuel injected for baseline conditions with no post-injection and WOT. At 500 bar the fuel mass required to maintain idle speed increased as the SOI of the $4^{\text {th }}$ injection was retarded, and throttling led to further increase in the amount of fuel. In 500 bar injection pressure case $50 \%$ more fuel was required with heaviest throttling compared to WOT for the same post-injection timing. However, for higher injection pressures the amount of fuel was nearly independent of post injection timing and slightly increased with lowered MAP. 


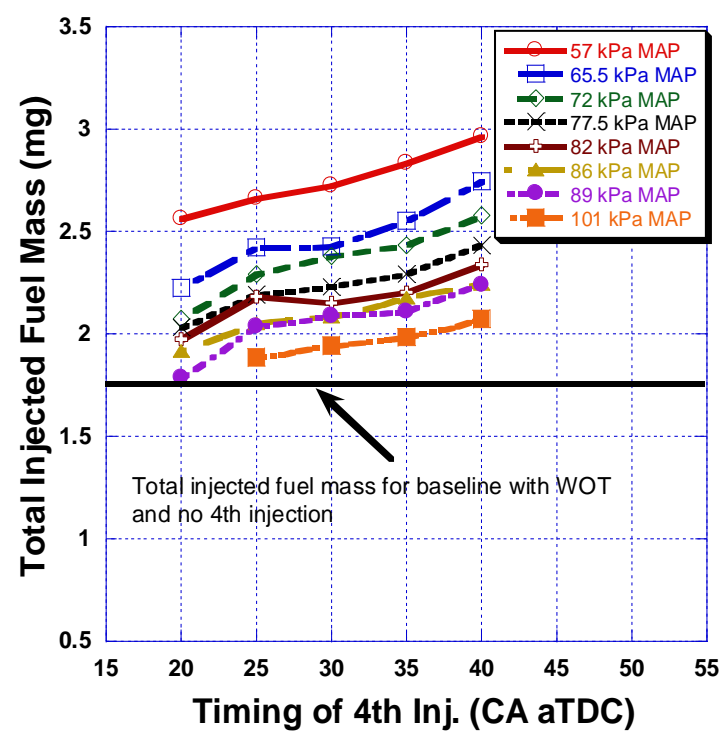

(a)

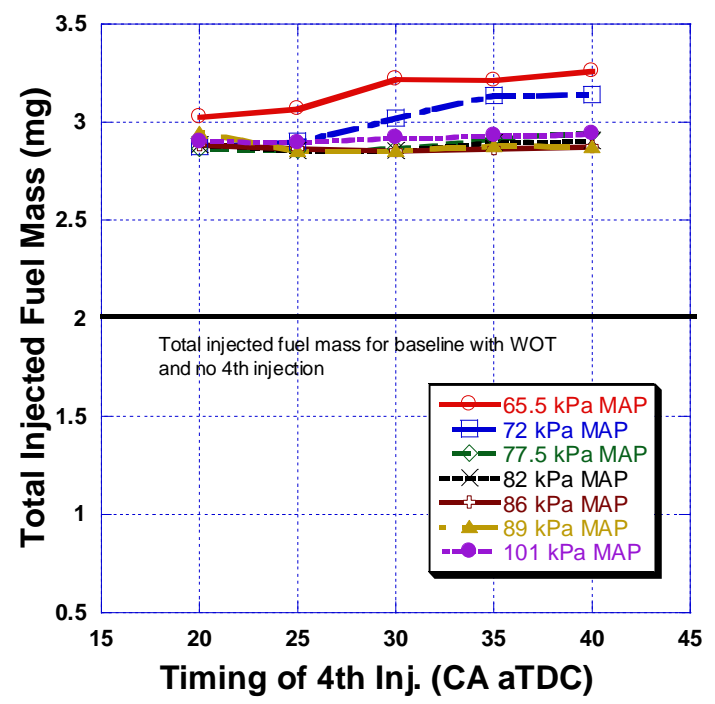

(b)

Figure 4-14 Total injection mass vs. post-injection timing for $850 \mathrm{rpm}$, relative to a baseline condition of WOT with no $4^{\text {th }}$ injection, (a) 500 bar, (b) 800 bar.

In Figure 4.15 the percentage increase in total injected fuel mass relative to the baseline condition with 500 bar injection pressure is shown. It is seen that fuel consumption 
increased by $90 \%$ when operating conditions changed from the baseline condition of WOT and no post-injection to the case of heaviest throttling and latest SOI of the $4^{\text {th }}$ injection. However, the exhaust temperature was insensitive to the SOI of the $4^{\text {th }}$ injection as shown above in Figure 4.6 thus for the same MAPs early SOI of post injection would increase temperature with less of a fuel consumption penalty.

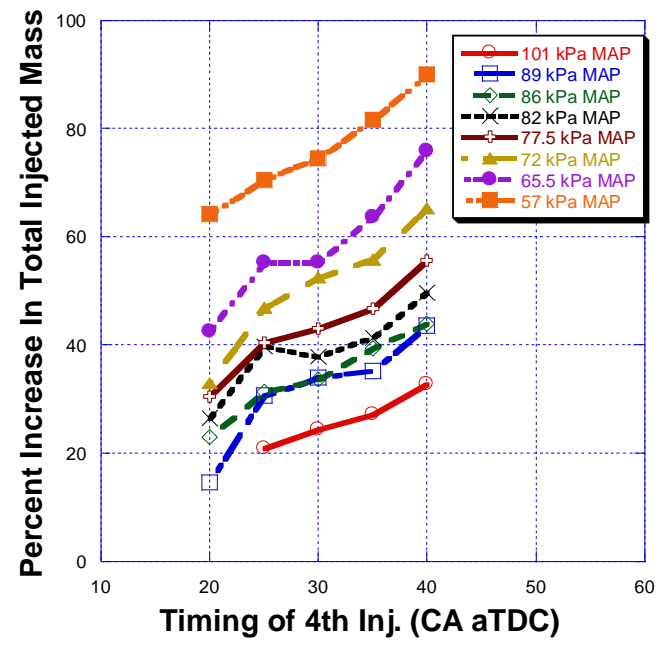

Figure 4-15 Percent increase in total injected fuel mass vs. SOI of post-injection for 850 rpm, 500 bar injection pressure

Figure 4.16 shows the percent increase in total injected fuel mass with decreasing MAP for the baseline injection strategy without the $4^{\text {th }}$ injection for the injection pressure of 500 bar and engine speed of 1100 and $850 \mathrm{rpm}$. It shows a similar trend to the exhaust temperature increase with MAP in Figure 4.10 and percent fuel increase grows approximately linearly with decreasing MAPs for both idle speed. It was observed that at $1100 \mathrm{rpm}$ for the heaviest throttling the increase in total injected fuel mass and exhaust temperature were $80 \%$ and $90 \mathrm{C}$, respectively while these values were nearly $65 \%$ and $50^{\circ} \mathrm{C}$ for $850 \mathrm{rpm}$. 


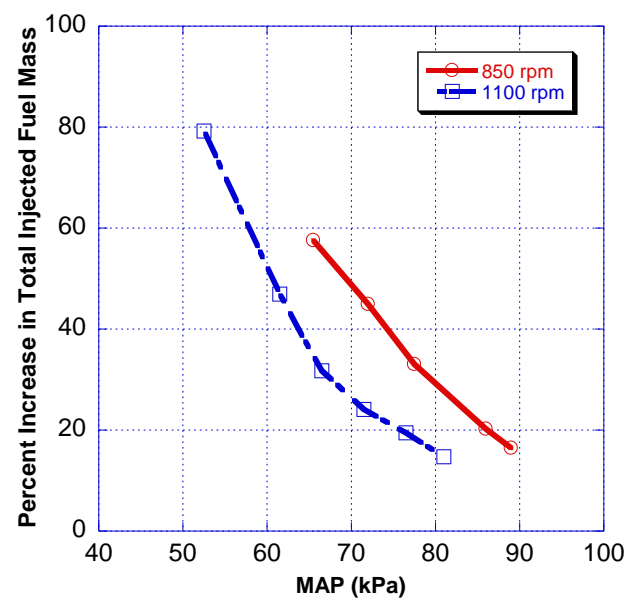

Figure 4-16 Percent increase in total mass vs. MAPs for Idle speed of 850 and $1100 \mathrm{rpm}$, no post-injection

Figure 4.17 shows the COV of IMEP for 500 and 800 bar injection pressures for the idle speed of $850 \mathrm{rpm}$. Variations in the COV for both injection pressure were very small compared to the significant variations in exhaust temperature, $\mathrm{NO}_{\mathrm{x}}$ and $\mathrm{HC}$ emissions. The COV values were slightly higher for 800 bar and declining trend was observed for both injection pressures for SOI of the $4^{\text {th }}$ injection after $30^{\circ} \mathrm{CA}$. It is seen that COV of IMEP was not a limiting factor of the operating conditions investigated in this study. 


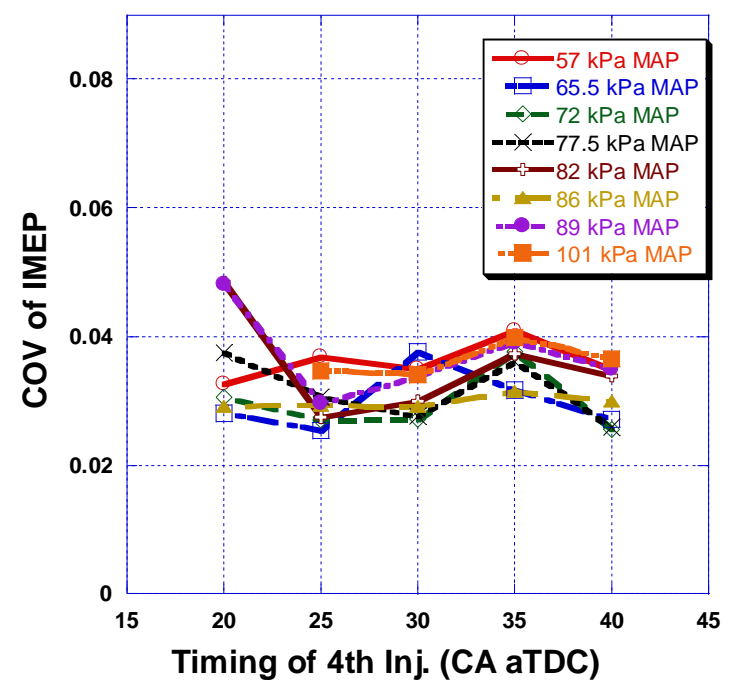

(a)

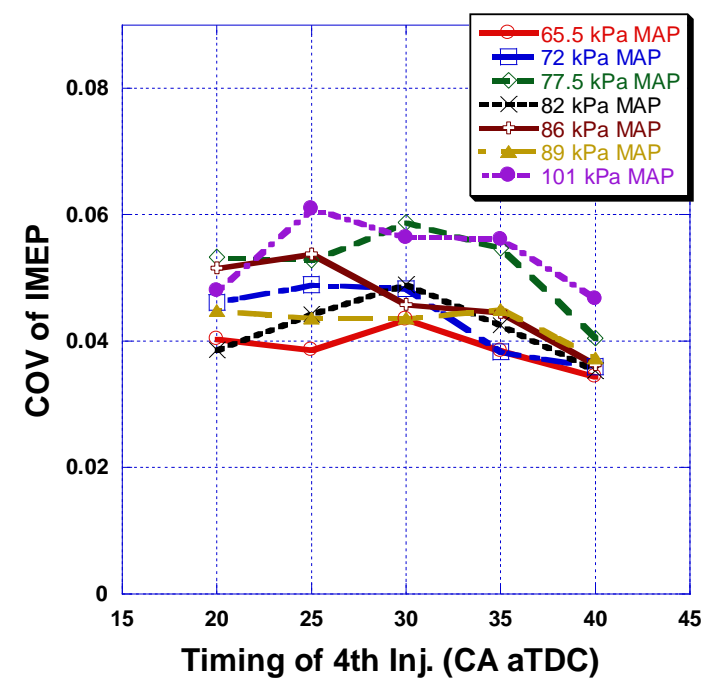

(b)

Figure 4-17 COV of IMEP vs. injection timing of $4^{\text {th }}$ injection for $850 \mathrm{rpm}$, (a) $500 \mathrm{kPa}$, (b) $800 \mathrm{kPa}$ 
Results showed that for the SOI of a $4^{\text {th }}$ injection beyond $30^{\circ} \mathrm{CA}$ the $\mathrm{HC}$ emissions increased and the exhaust temperature showed either a decreasing or stable trend for all of the engine operating parameters This led us to conclude that the upper limit for the SOI of the post-injection was approximately $30^{\circ} \mathrm{CA}$ due to incomplete combustion. For higher MAPs the exhaust temperature was nearly insensitive to the SOI of the post injection. However, for the heavy throttling cases for the 500 bar injection pressure, the maximum exhaust temperatures of $190^{\circ} \mathrm{C}$ at the idle speed of $850 \mathrm{rpm}$ and $230^{\circ} \mathrm{C}$ at $1100 \mathrm{rpm}$ were achieved for SOI of the $4^{\text {th }}$ injection 25 and $30^{\circ} \mathrm{CA}$, respectively. Figure 4.18 shows the exhaust temperature vs. MAP for the three idle speeds for the SOI of the post-injection $25^{\circ}$ and $30^{\circ} \mathrm{CA}$ and the injection pressure of 500 and 800 bar.

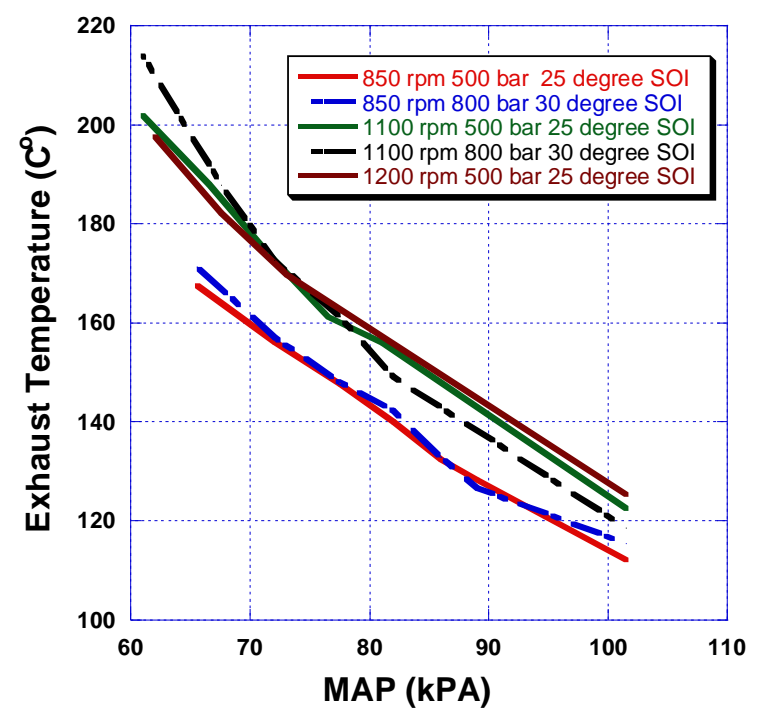

Figure 4.18 Exhaust temperature vs. MAP with 4th injection SOI of 25oCA aTDC for 500 bar injection pressure and 4th injection SOI of 30oCA aTDC for 800 bar injection pressure 
NOx emissions change with MAP for SOI of the $4^{\text {th }}$ injection 25 and $30^{\circ} \mathrm{CA}$ are shown in the Figure 4.19. NOx emissions rose with an increase in injection pressure and a decrease in idle speed.

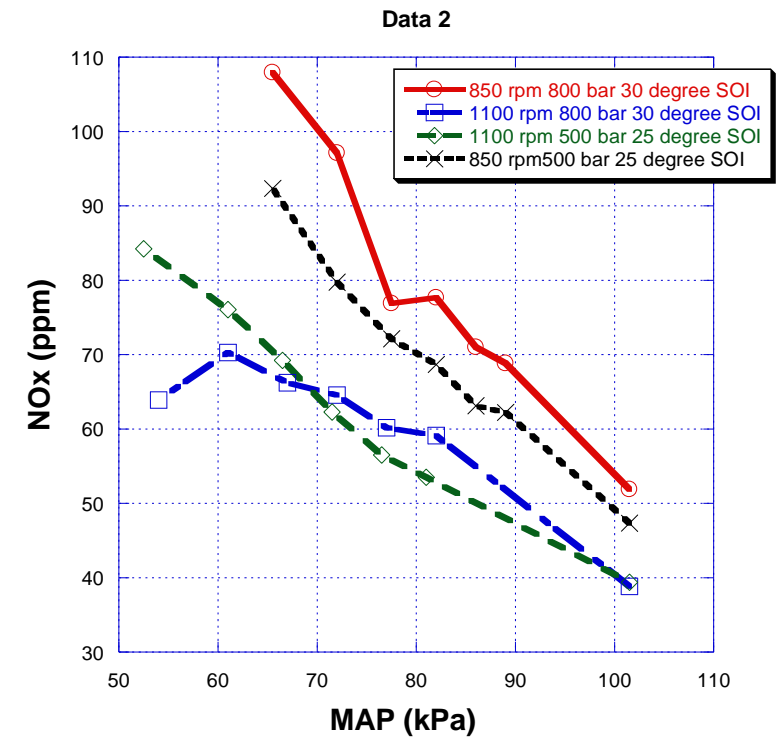

Figure 4.19 NOx emissions vs. MAP with 4th injection SOI of 25oCA aTDC for 500 bar injection pressure and 4th injection SOI of 30oCA aTDC for 800 bar injection pressure 


\section{Chapter 5: Conclusions and Future Work}

In this study the effects of injection pressure, engine speed and intake throttling on exhaust temperature and engine-out emissions of an idling light-duty diesel engine were investigated. A NI LabVIEW based engine control program was designed then applied to the engine through a c-RIO. The program was later successfully modified to meet the precise control demand for this experimental study. A PI based feedback loop for idle speed control was developed rather than using the motoring dyno to eliminate possible errors due to loading effect of the dyno. It also, allowed us to measure the fuel penalty associated with the above-mentioned strategies. Similar control loops were also developed for rail pressure

and throttle plate position control. All three engine parameters were controlled precisely with less $0.4 \%$ of error. The Control program could be further improved by an adding autotuning option to the algorithm so that no time will be spent on manually tuning the coefficients and the engine will maintain the desired setpoint value with less error rate throughout the experiment

For the baseline injection strategy, adapted from a Chevrolet Cruze engine, exhaust Temperature was measured approximately $105^{\circ} \mathrm{C}$ for the fully warmed-up idling engine with operating conditions of $850 \mathrm{rpm}$ idle speed, $101 \mathrm{kPa}$ of MAP and 500 bar injection pressure. It was found that temperature increased linearly as the MAP was reduced through intake throttling with no post injection. It was possible to increase exhaust temperature by $90^{\circ} \mathrm{C}$ with a higher idle speed of $1100 \mathrm{rpm}$ and the lowest MAP of $52 \mathrm{kPa}$. However, this led to $80 \%$ increase in total injected fuel mass. The exhaust temperature could be further increased by $25^{\circ} \mathrm{C}$ and it reached over $200^{\circ} \mathrm{C}$ by injecting fuel during the expansion stroke. The timing of the post injection varied between $20-40^{\circ} \mathrm{CA}$ aTDC and it was found that exhaust temperature was barely sensitive to injection timing and the temperature even 
decreased slightly beyond $25-30^{\circ} \mathrm{CA}$ SOI. Exhaust temperature for the same MAPs and post-injection timing did not show any significant difference for the higher injection pressure of 800 bar

$\mathrm{HC}$ emissions of nearly $60 \mathrm{ppm}$ for baseline idle conditions increased to approximately $240 \mathrm{ppm}$ with heaviest throttling and latest post-injection timing. It is necessary to mention that $\mathrm{HC}$ emissions increased as the post-injection was retarded while exhaust temperature was insensitive. For the similar MAPs and post-injection timings HC emissions were observed to be $20 \%$ higher for the higher engine speed of $1100 \mathrm{rpm}$.

The change of $\mathrm{NO}_{\mathrm{x}}$ emissions with throttling was similar to that of exhaust temperature and $\mathrm{HCs} . \mathrm{NO}_{\mathrm{x}}$ emissions increased as the MAP was reduced. With WOT and the same SOI of the $4^{\text {th }}$ injection $30 \%$ lower $\mathrm{NO}_{\mathrm{x}}$ emissions were observed for the 1200 rpm idle speed compared to $850 \mathrm{rpm}$. However, for heavy throttling the margin was smaller.

In future work the baseline injection strategy should be studied further to identify the best strategy that will better assist combustion of post injection beyond $30^{\circ} \mathrm{SOI}$ of postinjection. Also, additional to the techniques used in this experiment, effects of cylinder deactivation on exhaust temperature can be studied either separately or conjointly with above mentioned methods. A preliminary investigation showed cylinder deactivation can have a significant effect on exhaust temperature. 


\section{References}

[1] G. e. Gates, "new york times," New york times, 2015. [Online]. Available: https://www.nytimes.com/interactive/2015/business/international/vw-dieselemissions-scandal-explained.html. [Accessed 2017].

[2] J. Heywood, Internal Combustion Engine Fundamentals, McGraw-hill, 1988.

[3] M. McGhee, P. Shayler, A. LaRocca, M. Murphy and I. Pegg, "The Influence of Injection Strategy and Glow Plug Temperature on Cycle by Cycle Stability Under Cold Idling Conditions for a Low Compression Ratio, HPCR Diesel Engine," $S A E$ Int. J. Engines 5(3):923-937, 2012.

[4] "5. MacMillan, D., La Rocca, A., Shayler, J., Morris, T. et al., "Investigating the Effects of Multiple Pilot Injections on Stability at Cold Idle for a D1 Diesel Engine," SAE Technical Paper 2009-01-0612, 2009".

[5] "La Rocca, A., MacMillan, D., Shayler, P., Murphy, M. et al., "CFD Investigation on the Influence of In-Cylinder Mixture Distribution from Multiple Pilot Injections on Cold Idle Behaviour of a Light Duty Diesel Engine," SAE Technical Paper 2014-01-2708," 2014.

[6] "Bobba, M., Musculus, M., and Neel, W., "Effect of Post Injections on In-Cylinder and Exhaust Soot for Low-Temperature Combustion in a Heavy-Duty Diesel Engine," SAE Int. J. Engines 3(1):496-516, 2010, https://doi.org/10.4271/2010-010612.".

[7] EPA, "Idling Vehicle Emissions for Passenger,Light-Duty Trucks, and HeavyDuty," EPA, EPA420-F-08-025, 2008.

[8] U.S. Environmental Protection Agency (EPA), "Study of Exhaust Emissions from Idling Heavy-Duty Diesel Trucks and Commercially Available Idle-Reducing Devices," EPA, EPA420-R-02-025, 2002.

[9] Y. Huang and Q. Lu, "Huang, Y. and Lu, Q., "Thermal Management of a Four-way Catalyst System with Alternative Combustions for Achieving Future Emissions Standard," SAE Technical Paper 2007-24-0103, 2007, https://doi.org/10.4271/2007-24-0103".

[10] B. H.U. and O. O.A., "Effects of application of variable valve timing on the exhaust gas temperature improvement in a low-loaded diesel engine," Applied Thermal Engineering , vol. 122, pp. 758-767, 2017.

[11] S. Honardar, H. Busch, S. T., S. C. K. A.F. and K. T., "Exhaust Temperature Management for Diesel Engines Assessment of Engine Concepts and Calibration Strategies with Regard to Fuel Penalty,," 2011-24-0176, SAE International, 2011.

[12] World Health Organization, "Environmental health criteria 213 : Carbon monoxide," World Health Organization, Geneva, 1999. 
[13] R. I. A., A. K. and K. A, "Reşitoğlu, İ.A., Altinişik, K. \& Keskin, A. Clean Techn Environ Policy (2015) 17: 15. https://doi.org/10.1007/s10098-014-0793-9".

[14] D. Demers and G. Walters, Guide to exhaust emission control options, BAeSEMA, 1999, pp. 3-3.

[15] Environment Protection Agency, "How nitrogen oxides affect the way we live and breathe.," EPA ,EPA-456/F-98-005, 1998.

[16] S. Constantin and D. Mitu, "Simplified mechanism used to estimate the NOx emission of Diesel engine," in Advanced Manufaturing Engineering, Quality and Production Systems, Constantza, WSEAS Press, 2010, p. 61.

[17] Flagan, Richard C. and Seinfeld, John H. Fundamentals of Air Pollution Engineering. Prentice-Hall, Inc., Englewood CLiffs, NJ. 1988. ISBN 0-13-3325377. http://resolver.caltech.edu/CaltechBOOK:1988.001, p. 215.

[18] W. A. Majewski, "www.dieselnet.com," 02 2012. [Online]. Available: https://www.dieselnet.com/tech/cat_doc.php. [Accessed 611 2017].

[19] E. T. Isebella Nova, Urea SCR Technology for DeNOx After Treatment of Diesel Exhaust, London: Springer, 2014, pp. 14,68.

[20] R. Konrad, Diesel Engine Management, Friedrichshafen: Springer Vieweg, 2014, pp. 218-219.

[21] A. W. Majewski, "www.dieselnet.com/tech/dpm.php," 12 2016. [Online]. Available: https://www.dieselnet.com/tech/dpm.php. [Accessed 511 2017].

[22] B. Pundir, IC Engines Cumbustion and Emissions, India: Alpha Science, 2010, pp. 373-378.

[23] "Marco Piumetti, Samir Bensaid, Debora Fino \& Nunzio Russo (2015) Catalysis in Diesel engine NOx aftertreatment: a review, Catalysis, Structure \& Reactivity, 1:4, 155-173, DOI:10.1080/2055074X.2015.1105615," Catalysis, Structrure \& Reactivity, pp. 159-160, 2015.

[24] J. Calabrase, A. Patchett, K. Grimston and G. W. Rice, "The influence of injector operating conditions on the performance of a urea-water selective catalytic reduction(SCR) System," in Diesel Aftertreatment, Warrendale, SAE, 2000, p. 6.

[25] yokogawa, "www.yokogawa.com," yokogawa, [Online]. Available: https:/www.yokogawa.com/us/solutions/products-platforms/process-analyzers/gasanalyzers/ftnir-ir/. [Accessed 2211 2017].

[26] www.combustion.com, [Online]. Available: https://www.cambustion.com/products/hfr500/fast-fid-principles. [Accessed 2311 2017].

[27] www.Combustion.com, "www.Combustion.com," [Online]. Available: https://www.cambustion.com/products/hfr500/fast-fid-principles. [Accessed 2311 2017]. 
[28] Nationals Instrument , "www.ni.com," 2014. [Online]. Available:

http://www.ni.com/pdf/products/us/fullcriodevguide.pdf. [Accessed 20 November 2017].

[29] National Instrument, NI cDAQTM-9171/9174/9178 User Manual, Austin , 2016.

[30] National Instrument, "NI Combustion Analysis System Software for Labview,User's Manual". 